\title{
Rigorous optimization and validation of potent RNA CAR T cell therapy for the treatment of common epithelial cancers expressing folate receptor
}

\author{
Keith Schutsky ${ }^{1}$, De-Gang Song ${ }^{1}$, Rachel Lynn ${ }^{1}$, Jenessa B. Smith ${ }^{1}$, Mathilde \\ Poussin $^{1}$, Mariangela Figini ${ }^{2}$, Yangbing Zhao' ${ }^{1}$, Daniel J. Powell Jr., ${ }^{1,3}$ \\ ${ }^{1}$ Ovarian Cancer Research Center, Department of Obstetrics and Gynecology, Perelman School of Medicine, University of \\ Pennsylvania, PA 19104, Philadelphia \\ ${ }^{2}$ Department of Experimental Oncology and Molecular Medicine, Istituto Nazionale dei Tumori, 20133, Milan, Italy \\ ${ }^{3}$ Department of Pathology \& Laboratory Medicine, Abramson Cancer Center, Perelman School of Medicine, University of \\ Pennsylvania, PA 19104, Philadelphia
}

Correspondence to:

Daniel J. Powell, e-mail: poda@mail.med.upenn.edu

Keywords: folate receptor alpha, chimeric antigen receptor, adoptive immunotherapy, ovarian cancer, $T$ cells

Received: May 12, $2015 \quad$ Accepted: August 20, $2015 \quad$ Published: September 02, 2015

\section{ABSTRACT}

Using lentiviral technology, we recently demonstrated that incorporation of CD27 costimulation into CARs greatly improves antitumor activity and $\mathrm{T}$ cell persistence. Still, virus-mediated gene transfer is expensive, laborious and enables long-term persistence, creating therapies which cannot be easily discontinued if toxic. To address these concerns, we utilized a non-integrating RNA platform to engineer human $T$ cells to express FRa-specific, CD27 CARs and tested their capacity to eliminate human $\mathrm{FRa}^{+}$cancer. Novel CARs comprised of human components were constructed, $\mathrm{C4}-27 \mathrm{z}$ and $\mathrm{C40pt-27z}$, a codon-optimized variant created for efficient expression. Following RNA electroporation, C4-27z and C4opt-27z CAR expression is initially ubiquitous but progressively declines across $\mathrm{T}$ cell populations. In addition, C4-27z and C4opt-27z RNA CAR T cells secrete high levels of Th-1 cytokines and display strong cytolytic function against human $\mathrm{FR} \alpha^{+}$cancers in a time- and antigendependent manner. Further, C4-27z and C4opt-27z CAR T cells exhibit significant proliferation in vivo, facilitate the complete regression of fully disseminated human ovarian cancer xenografts in mice and reduce the progression of solid ovarian cancer. These results advocate for rapid progression of C4opt-27z RNA CAR to the clinic and establish a new paradigm for preclinical optimization and validation of RNA CAR candidates destined for clinical translation.

\section{INTRODUCTION}

Due to difficulties associated with genetically modifying primary $\mathrm{T}$ lymphocytes using non-viral based systems, investigators have generally utilized retroviral and lentiviral vectors in experiments that required high levels of transgene expression and viability in human $T$ cells [1-3]. However, several factors may restrict the use of viral vectors in clinical application including the time and cost required for viral vector production, restrictions on the size and number of genes that can be packaged into vectors, risk of insertional mutagenesis and possible safety issues associated with immune-mediated toxicity stemming from long-term persistence and activity of engineered $\mathrm{T}$ cells $[3,4]$. Adverse effects in patients related to administration of genetically-redirected $\mathrm{T}$ cells, including cytokine storm, cardiac arrhythmia, respiratory failure, seizures and even mortality have been reported using viral-based CAR T cell therapy [5-11]. In light of these potential events, a need exists for alternative, safe and effective gene transfer in T lymphocyte research, CAR development and clinical application.

Traditionally, gene transfection of $\mathrm{T}$ lymphocytes ex vivo has been problematic, often hindered by low 
transfection efficiency and irreversible toxicity caused by transfection agents acting on primary cell types, including T cells [12-15]. Although T lymphocytes are refractory to most kinds of nonviral gene delivery, RNA electroporation is emerging as a particularly useful strategy to introduce a gene of interest into T lymphocytes, and the concept of utilizing RNA therapeutically has received considerable attention during the past decade [3, 16]. Recently, it was reported that electroporation with RNA could be utilized to obtain high levels of CAR-T cell gene transfer efficiency and low electroporation-related apoptosis [3]. Furthermore, the transmission of CAR-based RNAs into $\mathrm{T}$ lymphocytes redirected these lymphocytes to recognize and destroy human leukemia in vivo, using various mouse models [17-21].

Hence, expression of CARs using a RNA platform represents an alternative method of potentially testing CARs clinically (with additional safety) where there may be concerns about possible cumulative "on-target, off-tumor" toxic effects, as the metabolism of RNA over time ensures complete removal of the CAR in the patient without relying on suicide induction systems. RNA CAR expression is self-limiting, serving as its own vehicle for toxicity attenuation. In contrast to longer-term, integrating viral expression systems, RNA transfection may permit rapid iterative changes in CAR design and the possibility of moving toward a good manufacturing practice (GMP)compliant system with potentially lower expenses and less complicated pharmacokinetic testing as opposed to lentiviral or retroviral vectors $[17,19]$. The RNA CAR approach may be limited, however, in situations where long-term CAR expression is required for complete response (i.e. bulky, aggressive solid tumor malignancies) or when repeated $\mathrm{T}$ cell infusion is not possible [22].

Long-term CAR T cell persistence and increased $\mathrm{T}$ cell activity can be achieved by addition of costimulatory domains to the intracellular portion of the CAR construct. Costimulatory endodomains from CD28, CD134 (OX-40) and CD137 (4-1BB) in CARs significantly enhances the ability of CAR T cells to secrete cytokines, proliferate, persist and produce antitumor effects in rodents [9-11, 23-28]. Similarly, CAR therapy utilizing one or more costimulatory molecule domains $\left(2^{\text {nd }}\right.$ and $3^{\text {rd }}$ generation CARs) have shown considerable benefit in patients with lymphoma and other cancers [29, 30]. Recently, we demonstrated that the costimulatory molecule, CD27, actively enhances CAR T cell function, expansion and survival in vivo $[28,31]$. Human $\mathrm{T}$ cells virally transduced to express a folate receptor- $\alpha(\mathrm{FR} \alpha)$-specific CAR, comprised of an extracellular murine anti-human $\mathrm{FR} \alpha$

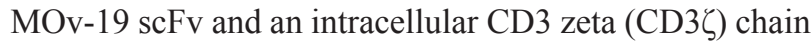
signaling module in tandem with a CD27 costimulatory endodomain displayed enhanced cytokine release, cytolytic function and proliferation in vivo, thereby rationalizing the incorporation of CD27 costimulation in CAR-T therapy for FR $\alpha+$ cancer.
Elevated expression of the glycosylphosphatidylinositol-anchored protein, $\mathrm{FR} \alpha$, occurs in many human malignancies, including ovary, breast, kidney, lung, colon, rectum, head, neck and brain cancers [32-38], and is limited in normal tissues [39]. Recently, it was suggested that the degree of $\mathrm{FR} \alpha$ content in a tumor may be utilized for prognostic purposes, with higher expression being especially deleterious [32]. Notably, the number of human tumors reported to express FR $\alpha$ is rapidly growing [39]. Therefore, CAR-T cell therapies specifically targeting FRamay be of considerable benefit in the clinic. While $90 \%$ of ovarian cancers (OC) over-express FR $\alpha$, the vast majority of somatic tissues do not, making this cancer type particularly relevant when examining the efficacy of FR $\alpha$ CAR T cell therapies and their potential for immune toxicity $[33,39]$. Moreover, OC ranks as the fifth leading cause of cancer mortality among women, with one in 70 females developing OC in her lifetime [40]. Currently, there are no diagnostics for early detection, and the majority of these cancers are not diagnosed until the cancer has metastasized, making the disease extremely difficult to treat. Hence, CAR-T cell based therapies that effectively combat OC, when widely disseminated, would be extremely beneficial. Although viral CAR-T cell therapies have been shown to effectively combat OC in preclinical models, there are no reports of clinically effective RNA CAR-T cell therapies in OC [28, 41-43].

To bring safe, effective therapy to OC patients, we utilized an RNA platform to create and test two novel FR $\alpha$-specific CARs, C4-27z and C4opt-27z, which, when electroporated as RNA into primary human T lymphocytes, lead to efficient, but transient, CAR expression. Unlike, past FR $\alpha$-specific CARs [31, 44, 45], these CARs are fully human in composition with reduced risk for inducing transgene immunogenicity and anaphylaxis which can accompany use of CARs bearing murine components [44, 46]. Furthermore, the C4-opt-27z CAR is codon optimized for efficient expression in human T cells. Importantly, robust surface expression of these CARs on T cells leads to vigorous Th-1 cytokine secretion and potent cytolytic activity against a number of FR $\alpha$-expressing ovarian cancer lines. Further, multiple injections of $\mathrm{T}$ lymphocytes expressing C4-27z or C4opt-27z CAR provide complete remission against fully disseminated human ovarian tumor xenografts in rodents, which correlates with significant $\mathrm{CD}^{+}$and $\mathrm{CD}^{+} \mathrm{T}$ cell expansion in peripheral blood. C4-27z and C4opt-27z RNA CAR therapy also significantly reduce the progression of solid ovarian cancer in vivo. Notably, codon optimization of the CAR modestly, but reproducibly, improved cancer cell killing in vitro and in vivo under suboptimal treatment dosing schedule, making it a strong candidate for use in clinical application in patients with FR $\alpha$-expressing cancers. 


\section{RESULTS}

\section{CAR construction}

$\mathrm{FR} \alpha$-specific CARs containing the fully human scFV $\mathrm{C} 4$, which has specificity for FR $\alpha$ [47], were constructed. $\mathrm{FR} \alpha$ constructs were composed of the $\mathrm{C} 4 \mathrm{scFv}$ linked to a $\mathrm{CD} 8 \alpha$ hinge and transmembrane region, followed by a $\mathrm{CD} 3 \zeta$ signaling moiety in tandem with the $\mathrm{CD} 27$ intracellular signaling motif (C4-27z, Figure 1A). To increase the efficiency of CAR expression and address the potential for off-frame transcription, codons were optimized and all internal open reading frames (ORFs) were removed with one exception, creating the $\mathrm{C} 4$ opt- $27 \mathrm{z}$ CAR. A single ORF in the reverse complement strand at nucleotide position 1511 could not be removed as a switch from CAC to CAT (His at amino acid position 493) which would have created a new ORF in the antisense strand. Fortunately, a stop codon starting at position 1496 ensured that this internal ORF would only yield a five amino acids peptide (H-L-A-D-Y), if ever translated, too small to produce an immunologically functional protein. A CD19-specific CAR containing $\mathrm{CD} 3 \zeta$ and $\mathrm{CD} 27$ signaling motifs (CD19-27z) was constructed to control for antigen specificity. CAR constructs were subcloned into a pD-A.lenti cloning site. $2 \mathrm{bg} .150 \mathrm{~A}$ vector (PDA) that was optimized for $\mathrm{T}$ cell transfection, CAR expression and RNA production [18]. Transgene expression was driven by the $\mathrm{T} 7$ promoter.

\section{RNA electroporation of human $T$ cells results in high CAR expression efficiency and viability}

RNA gene transfer technology established for clinical application was used, as previously described $[19,48]$. The RNA-based, PDA vector was utilized to transfect human $\mathrm{T}$ cells which then efficiently expressed anti-FR $\alpha$ or anti-CD19 CARs (Figure 1B-1D). Strikingly, transfection efficiency for $\mathrm{C} 4-27 \mathrm{z}, \mathrm{C} 4 \mathrm{opt}-27 \mathrm{z}$ and CD19-27z CAR T cells approached $100 \%$ during the first $24 \mathrm{hr}$, declining at a rate similar in $\mathrm{CD}^{+}, \mathrm{CD}^{+}$and $\mathrm{CD}^{+} \mathrm{T}$ cell populations (Figures $1 \mathrm{~B}-1 \mathrm{D}, 1 \mathrm{E}, 1 \mathrm{H}, 1 \mathrm{~K}$ ). Reproducibly, electroporation with C4opt-27z RNA resulted in higher levels of surface CAR expression than with the parental $\mathrm{C} 4-27 \mathrm{z}$, indicating enhanced translation and expression. Importantly, transgene surface expression was detectable up to 10 days after RNA electroporation in C4-27z, C4opt-27z and CD19-27z CAR T cells. Viability for $\mathrm{CD}^{+}, \mathrm{CD}^{+}$and $\mathrm{CD} 8^{+} \mathrm{T}$ cells after $\mathrm{CAR}$ electroporation was $\sim 65-80 \%$ during the course of experiments, indicating that neither electroporation nor transgene expression caused irreversible damage or significantly affected $\mathrm{T}$ cell health (Figures 1F, 1I, 1L). CAR T cell expression, viability and the rate of CAR expression loss were dependent on the concentration of input RNA (Supplemental Figures 1A-1I). In general, higher concentrations of RNA produced greater CAR $\mathrm{T}$ cell expression for longer periods at the expense of viability during the first $24-72$ hours following electroporation, although $\mathrm{T}$ cells recovered in media containing 50-100 IU/mL IL-2, regardless of RNA concentration. Notably, after 24 hours of coincubation with FR $\alpha$-expressing cancer cells (SKOV3), C4-27z and C4opt-27z, but not CD19-27z, CAR expression declined rapidly in $\mathrm{CD}^{+}, \mathrm{CD}^{+}$or $\mathrm{CD} 8^{+} \mathrm{T}$ cells, consistent with $\mathrm{T}$ cell activation and metabolism resulting in a greater loss of RNA-transcribed CAR expression (Figures 1G, Supplemental Figures 2A-2B). Conversely, CAR expression of $\mathrm{C} 4-27 \mathrm{z}$ and $\mathrm{C} 4 \mathrm{opt}-27 \mathrm{z}$ T cells was not affected after co-incubation with $\mathrm{FR}^{-} \mathrm{C} 30$ cancer cells (Figure 1J), suggesting that CAR activation is antigen $(\mathrm{FR} \alpha)$-specific.

\section{C4 and C4opt CAR T cells with CD27z signaling exert antigen-specific reactivity in vitro}

Ninety percent of human ovarian cancers express FR $\alpha$, making such cancers particularly useful to examine functional activity of FR $\alpha$-specific CAR T lymphocytes $[33,39]$. Thus, a panel of established human ovarian cancer lines that express surface FR $\alpha$ at various levels were selected for immune assays (Figures 2A-2B). Flow cytometry results confirmed that ovarian cancer lines SKOV3, A1847, OVCAR3 and A2780 expressed surface FR $\alpha$ protein, as did a control line AE17.FR $\alpha$ (a mouse mesothelioma line engineered to express human FR $\alpha$ ). K562.CD19 (a human erythomyeloblastoid leukemia cell line engineered to express human CD19) served as a control for CD19-27z CAR functions. C30, parental AE17, K562 and engineered K562.CD19 lines were mostly negative for FR $\alpha$.

To evaluate the extent of $\mathrm{C} 4-27 \mathrm{z}$ and $\mathrm{C} 4 \mathrm{opt}-27 \mathrm{z}$ antigen-specific reactivity in vitro, CAR RNA electroporated $\mathrm{T}$ cells and cancer cells were cocultured overnight and $\mathrm{T}$ cell reactivity was measured by proinflammatory cytokine secretion. C4-27z and C4opt-27z CAR T cells exclusively recognized $\mathrm{FR}^{+}$ovarian cancer lines, secreting high levels of Th- 1 cytokines, including IFN- $\gamma$, IL-2, TNF- $\alpha$ and MIP-1A (Figures 3A-3B, 3F-3G, 3K-3L, 3P-3Q). Release of these Th- 1 cytokines was FRaand CAR specific, as $\mathrm{C} 4-27 \mathrm{z}$ and $\mathrm{C} 4 \mathrm{opt}-27 \mathrm{z}$ CAR $\mathrm{T}$ cells produced little or undetectable levels of cytokines when stimulated by $\mathrm{FR} \alpha$ cell lines, including C30, AE17, K562, and K562.CD19. C4-27z and C4opt-27z CAR T lymphocytes secreted low, but reliably detectable levels of Th-2 cytokines, including IL-4 and IL-10, in response to $\mathrm{FR}^{+}$cancer cells (Supplemental Figures 3A-3B, 3D-3E) although the response was considerably Th-1 biased. As expected, CD19-27z CAR T cells did not produce appreciable levels of cytokines after coculture, except when coincubated with K562.CD19 cells (Figures 3C, 3H, 3M, 3R). In addition, non-electroporated $\mathrm{T}$ cells, mock RNA electroporated $\mathrm{T}$ cells (containing no RNA), and cancer lines themselves did not secrete appreciable levels of cytokines (Figures 3D, 3I, $3 \mathrm{~N}, 3 \mathrm{~S}$ ), illustrating a requirement for antigen-specificity in CAR T cell reactivity. Notably, levels of cytokine production 
exhibited by C4opt-27z RNA CAR T cells were dependent on the concentration of RNA used for electroporation, reaching a maximum at $5 \mu \mathrm{g}$ RNA (Supplemental Figure 4A). In addition, non-specific cytokine secretion by CD19-27z CAR T cells increased at successively higher RNA concentrations in parallel cocultures (Supplemental Figure 4A). Interestingly, C4opt-27z and CD19-27z CAR $\mathrm{T}$ cells electroporated with escalating doses of RNA and then cocultured overnight with $\mathrm{FR} \alpha^{-} \mathrm{C} 30$ tumor displayed dose-dependent (but antigen-independent) CAR reactivity (Supplemental Figure 4B). Together, these results suggest that lower RNA concentrations $(\sim 5 \mu \mathrm{g})$ may be used to obtain nearly optimal FR-specific effects while minimizing the baseline of non-specific immune activation.

Importantly, optimization of $\mathrm{C} 4-27 \mathrm{z}$ did not negatively impact function, as $\mathrm{C} 4 \mathrm{opt}-27 \mathrm{z}$ CAR $\mathrm{T}$ cells were equally, and often more, immunoreactive than C4-27z CAR T cells, which is consistent with equivalent, if not higher, levels of C4opt scFv CAR expression on the cell surface, compared to C4 CAR (Figures 1B-1D, 1E, $1 \mathrm{H}, 1 \mathrm{~K})$. In addition, $\mathrm{CD}^{+}$and $\mathrm{CD}^{+} \mathrm{T}$ cells that were isolated, expanded and electroporated separately with

A

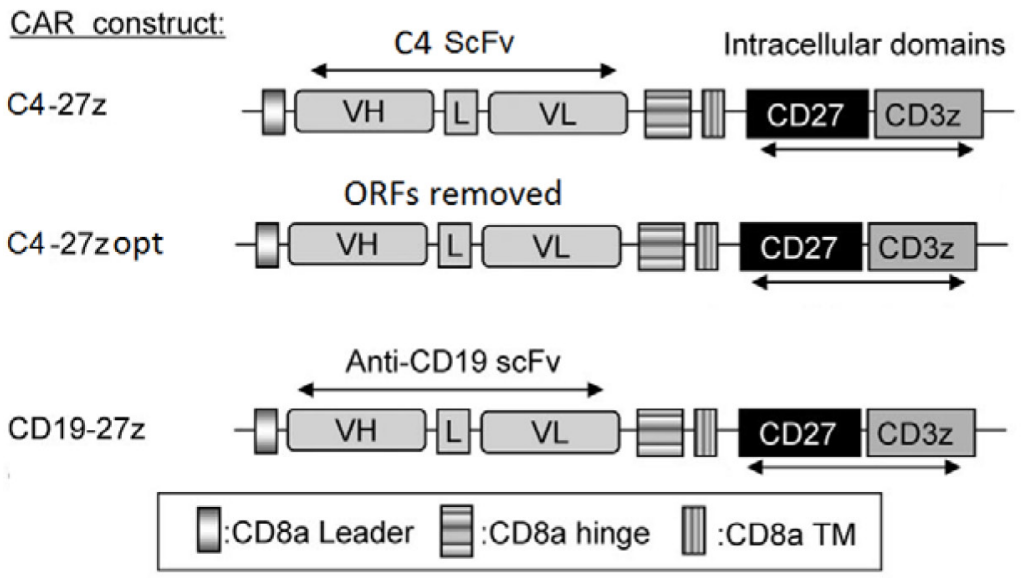
B Days Post Electroporation
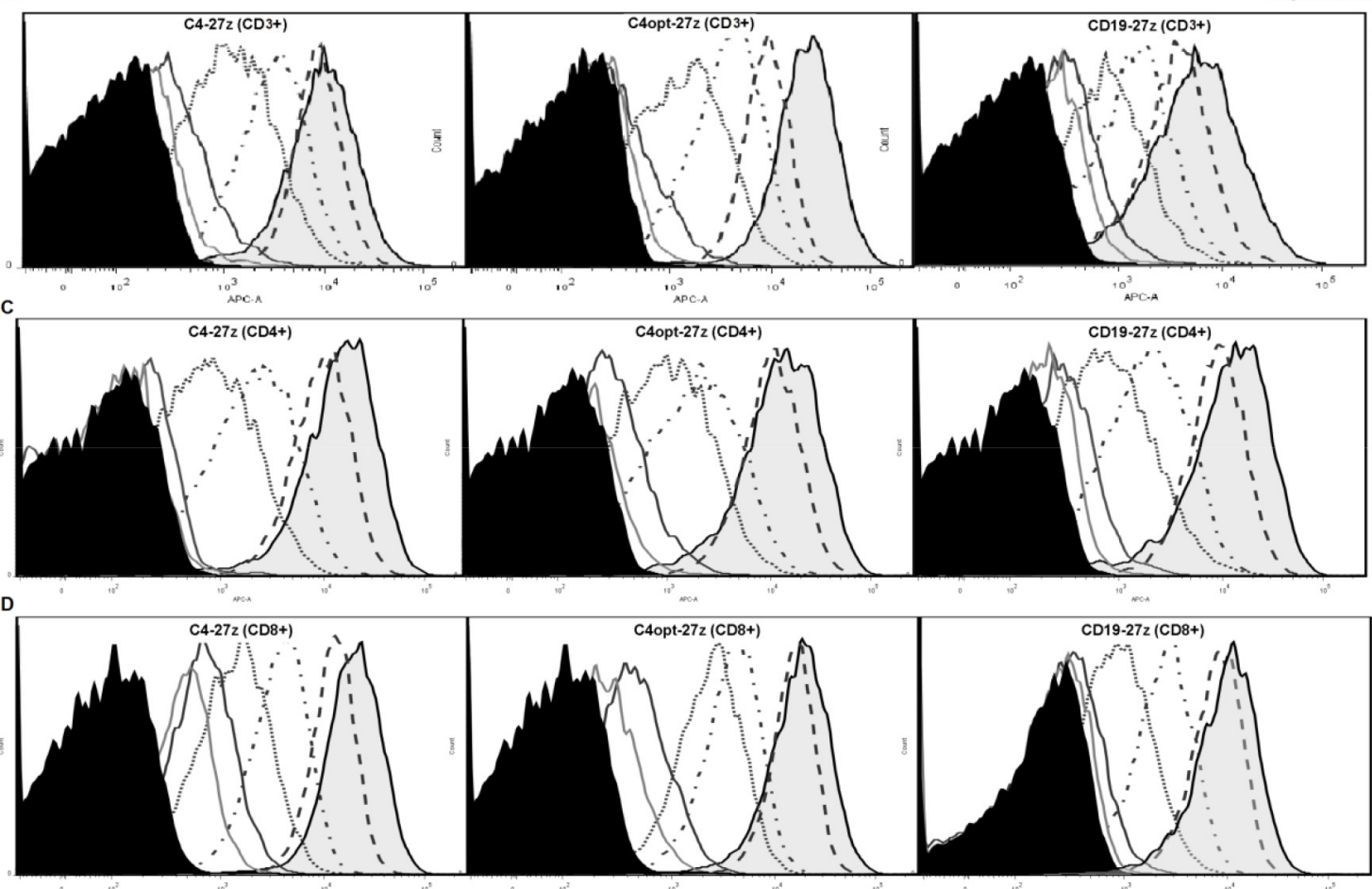

Figure 1: Generation, expression and viability of FRo-specific CAR-transfected human T lymphocytes in vitro. A. A

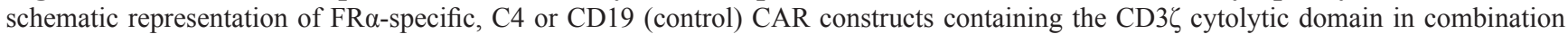
with the CD27 costimulatory molecule. VL, variable light chain; L, linker; VH, variable heavy chain; TM, transmembrane region.

(Continued) 

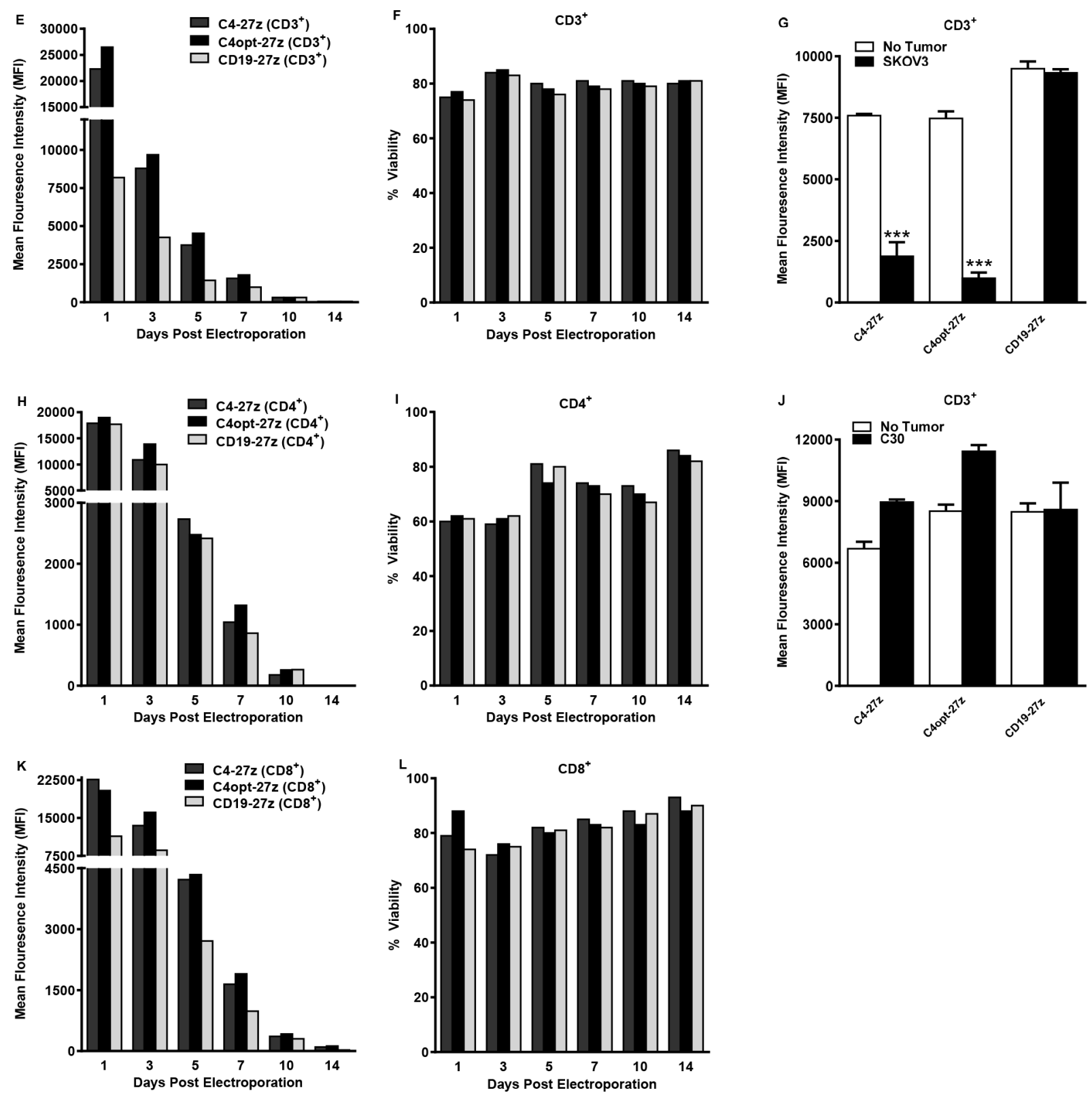

Figure 1: (Continued) B-D,E, H, K. CAR expression as measured by APC-A or change in mean fluorescence intensity (MFI) at different time points after electroporation with $\mathrm{C} 4-27 \mathrm{z}, \mathrm{C} 4$ opt $-27 \mathrm{z}$ or CD19-27z RNA. Electroporated CD3 ${ }^{+}, \mathrm{CD}^{+}{ }^{+}$or CD8 ${ }^{+} \mathrm{T}_{\text {cells }}$ (containing no RNA) were used as negative controls (filled histograms). F, I, L. Cell viability was detected using 7-AAD (BD Viaprobe). G, H. Expression of C4-27z and C4opt-27z, but not CD19-27z (control CAR) declines rapidly (measured at $72 \mathrm{hr}$ ) after $24 \mathrm{hr}$ coincubation with FR $\alpha^{+}$ SKOV3 tumor on day 1 (student $t$ test, $p<.001$ ). Conversely, expression of C4-27z, C4opt-27z and CD19-27z do not change after co-incubation with $\mathrm{FR} \alpha^{-} \mathrm{C} 30$.

C4-27z or C4opt-27z CARs displayed robust reactivity, with each population producing Th-1 type cytokines in a FR $\alpha$-dependent manner, and each population exhibiting a Th-1 response (Supplemental Figures 5A-5B, 5D-5E, $5 \mathrm{G}-5 \mathrm{H}, 5 \mathrm{~J}-5 \mathrm{~K})$. Generally, CD4 ${ }^{+} \mathrm{CAR}$ T cells preferentially secreted IL-2 whereas $\mathrm{CD}^{+} \mathrm{CAR}$ T cells produced more IFN- $\gamma$. However, both $\mathrm{T}$ cell populations were able to produce IL-2 and IFN- $\gamma$ in relatively high amounts although at levels less than total $\mathrm{CD}^{+} \mathrm{CAR} \mathrm{T}$ cells, suggesting synergy between $\mathrm{CD}^{+}$and $\mathrm{CD}^{+} \mathrm{CAR}$ T cells in mediating the proinflammatory response. Finally, we tested if cytokine production by $\mathrm{FR} \alpha$-specific CAR $\mathrm{T}$ cells declined in a manner consistent with CAR expression level. CAR T cells, at progressively later times after RNA electroporation when CAR expression declines, were cocultured with $\mathrm{FR}^{+}$tumor lines overnight. Indeed, C4-27z and C4opt-27z RNA CAR T cells progressively secreted significantly lower levels of cytokines 3, 6 and 10 days post-electroporation and did not produce elevated levels of IFN- $\gamma$ or IL-2 at day 14 when CAR expression was expired (Figures $3 \mathrm{U}-3 \mathrm{X}$ and $1 \mathrm{~B}-1 \mathrm{D}$ ). 

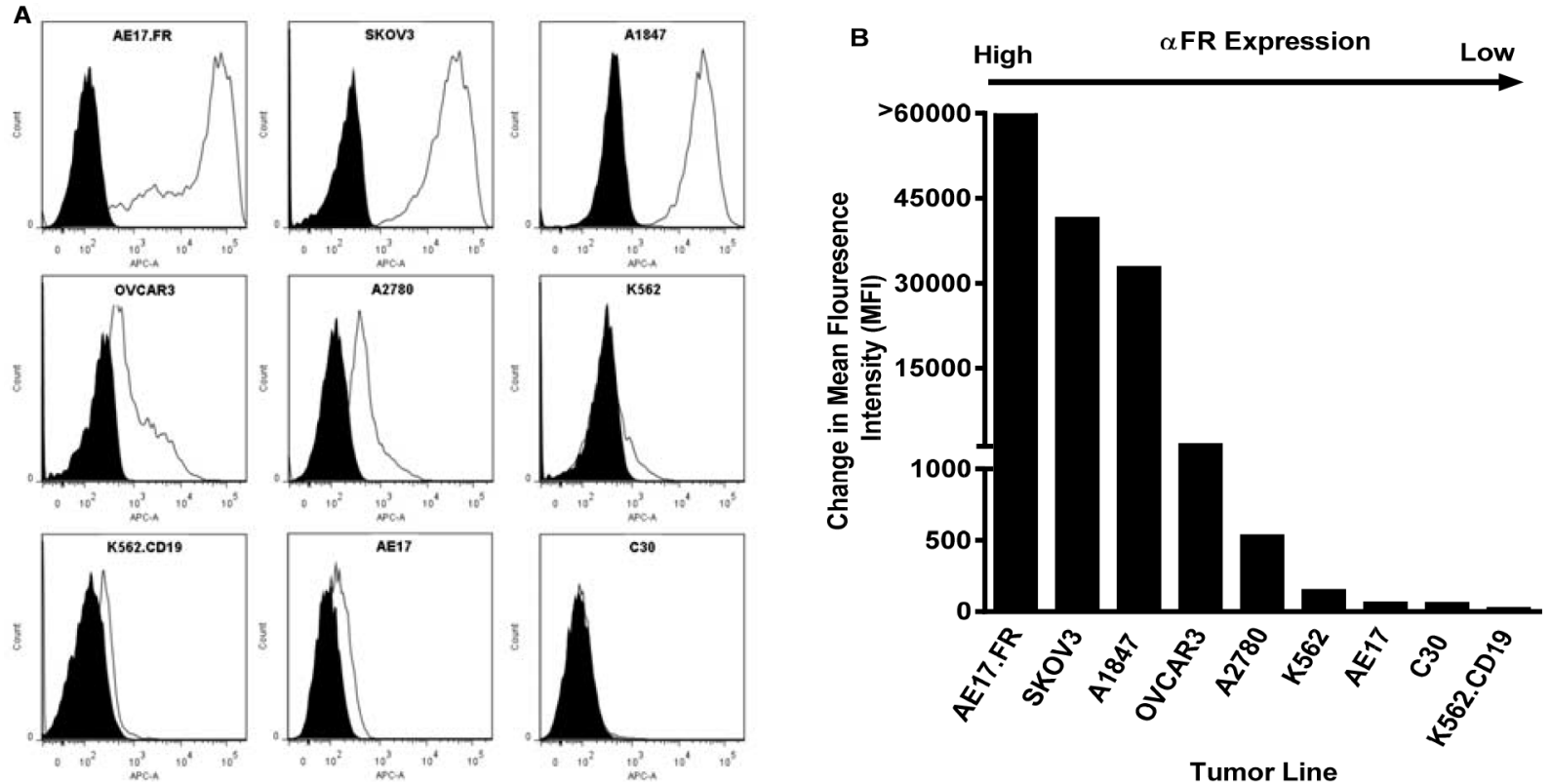

Figure 2: FR $\alpha$ surface expression of human ovarian cancer cell lines by flow cytometry. A. FR $\alpha$-specific mAb MOv18 was used to measure FR $\alpha$ expression of tumor cell lines by flow cytometry (open histogram), compared with IgG1 isotype controls (filled grey histogram). B. FR $\alpha$ expression as measured by the change in mean fluorescence intensity (MFI).

\section{C4-27z, C4opt-27z CAR T cells display potent cytolytic function in vitro}

Next, we assessed the FR $\alpha$-specific cytolytic potential of RNA electroporated C4-27z, C4opt-27z and CD19-27z CAR T cells in vitro. RNA CAR T cells were cocultured overnight with FR $\alpha^{+}$SKOV3, A1847, OVCAR3 or FR $\alpha^{-}$C30 cancer cells expressing firefly luciferase and then assessed for bioluminescence. Luminescence results displayed in Figures 4A-4D reveal that $\mathrm{C} 4-27 \mathrm{z}$ and $\mathrm{C} 4 \mathrm{opt}-27 \mathrm{z}$ CAR $\mathrm{T}$ cells specifically destroyed $\mathrm{FR}^{+}$SKOV3, A1847 and OVCAR3 but not $\mathrm{FR} \alpha^{-} \mathrm{C} 30$ cells. Moreover, non-electroporated T cells, mock RNA electroporated T cells and CD19-27z CAR T cells did not appreciably lyse any of the control cancer lines tested. In general, C4opt-27z CAR T cells showed enhanced or comparable cytolytic potential compared to $\mathrm{C} 4-27 \mathrm{z}$ CAR T cells. Interestingly, FR $\alpha$-specific lytic function of C4opt-27z CAR T lymphocytes was dependent on the concentration of RNA utilized for electroporation (Supplemental Figure 6A). In addition, non-specific lysis by CD19-27z CAR T cells increased at successively higher RNA concentrations (Supplemental Figure 6B), mirroring cytokine release. C4opt-27z and CD19-27z CAR T cells also displayed elevated levels of antigen-independent lysis when electroporated at high RNA concentrations and then cocultured with FR $\alpha^{-}$C30 cells (Supplemental Figures 6C-6D). Hence, low to moderate RNA concentrations may discriminate between FR $\alpha$-specific effects and nonspecific activation of CAR $\mathrm{T}$ cells themselves due to RNA electroporation. $\mathrm{CD}^{+} \mathrm{C} 4-27 \mathrm{z}$ and $\mathrm{C} 4 \mathrm{opt}-27 \mathrm{z}$ CAR
T cells display greater cytolytic function than $\mathrm{CD} 4{ }^{+} \mathrm{C} 4$ CAR T cells, particularly at high E/T ratios (Supplemental Figures 7A-7B), and similar levels of non-specific lysis (Supplemental Figures 7C-7D). Finally, we examined the cytolytic potential of C4-27z and C4opt-27z CAR T cells as a function of time. Similar to the rate of decline in CAR expression and cytokine production (Figures 1B-1D, 1E, $1 \mathrm{H}, 1 \mathrm{~K}, 3 \mathrm{U}-3 \mathrm{X}), \mathrm{C} 4-27 \mathrm{z}$ and $\mathrm{C} 4 \mathrm{opt}-27 \mathrm{z}$ CAR $\mathrm{T}$ cell killing potential decreased in a time-dependent fashion, returning to baseline levels 14 days after electroporation (Figure 4E-4N).

\section{C4-27z, C4opt-27z CAR T cells exhibit proliferation and potent antitumor function in vivo}

Because of the extensive FR $\alpha$-specific effector functions displayed by C4-27z and C4opt-27z RNA CAR $\mathrm{T}$ lymphocytes in vitro, we rigorously tested whether these RNA CAR T cells would mediate regression of human cancer in vivo. Immunodeficient non-obese diabetic/severe combined immunodeficiency/IL-2R $\gamma \mathrm{c}^{\text {null }}$ (NSG) mice were inoculated intraperitoneally (i.p.) or subcutaneously (s.c.) with $5 \times 10^{6} \mathrm{fLuc}^{+} \mathrm{SKOV} 3$ human ovarian cancer cells. Randomized mice then received one of three treatment regimens depending on the route of inoculation, with i.p. treatments commencing at day 14 and intratumoral treatments on day 21 (see Figure Supplemental 8A-8C for schedules). Regimen one consisted of three i.p. injections of $10^{7}$ CAR T cells (10-10-10) spaced three days apart in animals inoculated i.p. with SKOV3 cells (Figure 5). 

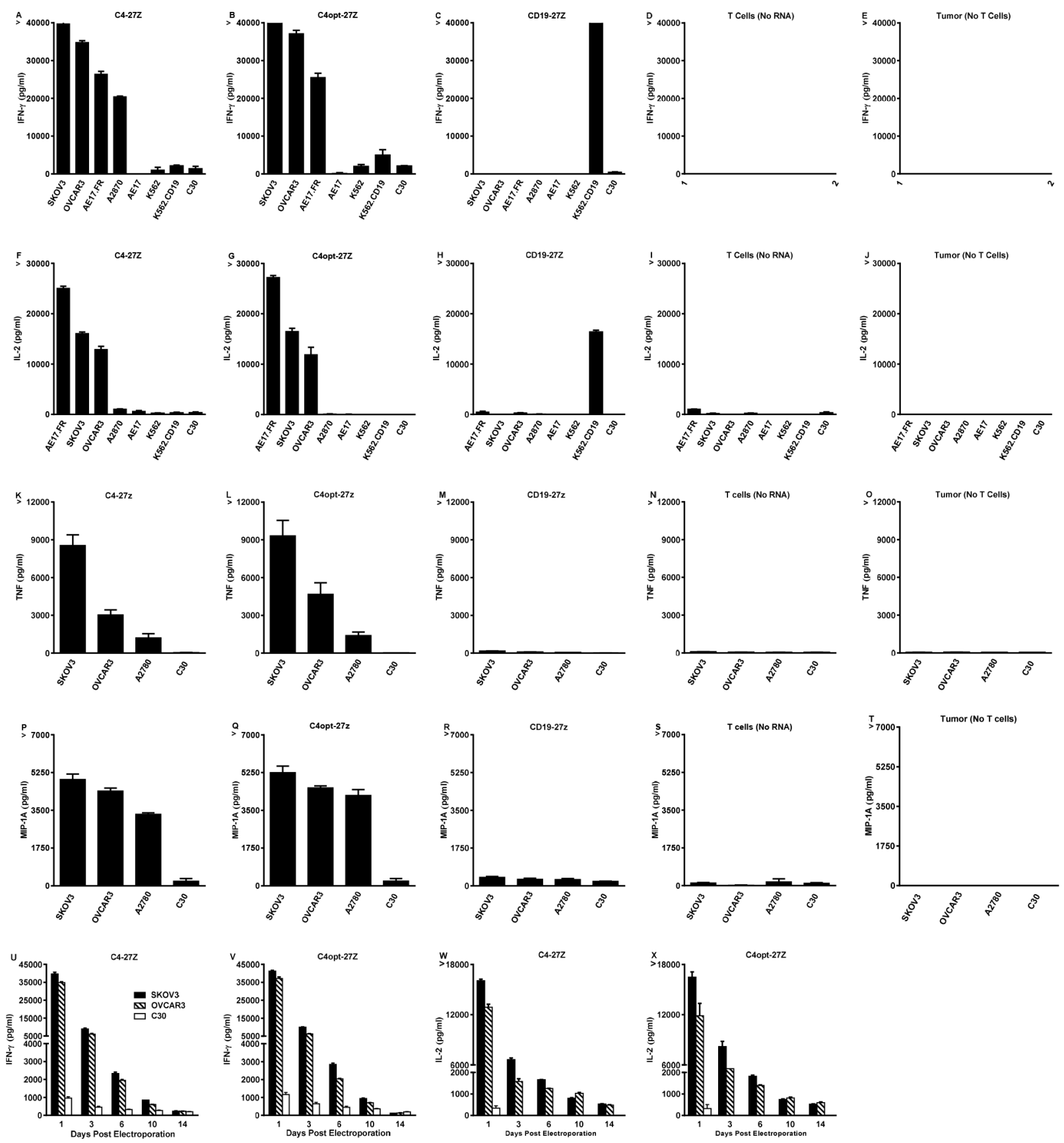

Figure 3: High levels of Th-1 cytokines are secreted by electroporated C4-27z and C4opt-27z RNA CAR T cells in response to $\mathbf{F R a}^{+}$tumor cells. A-B, D-E. Antigen-specific IFN- $\gamma$ \& IL-2 cytokine production by FR $\alpha$-specific RNA CAR-transfected $\mathrm{T}$ cells $\sim 24 \mathrm{hr}$ after coculture with the indicated tumor lines at a 1:1 ratio, measured with Elisa. C, F. CD19-27z CAR-T cells were used as negative controls. G-L. TNF- $\alpha$ and MIP-1A production was measured by human cytometric bead array (CBA) according to manufacturer's instructions. Non-electroporated T cells, electroporated T cells (containing no RNA) and tumor lines themselves did not produce appreciable levels of any cytokine (data not shown). M-P. Release of IFN-g \& IL-2 declines with time and is dependent on the interval between RNA CAR electroporation and coincubation. Results are expressed as a mean $+/-$ SEM of triplicate wells from 1 of at least 2 separate experiments.

In regimen two, i.p. inoculated SKOV3-bearing rodents were administered $2 \times 10^{7}$ CAR-T cells (a loading dose) followed by weekly doses of $10^{7} \mathrm{CAR}-\mathrm{T}$ cells for two weeks (maintenance doses; 20-10-10 i.p., Figure 6). A third regimen examined C4opt-27z CAR T cell therapy delivered intratumorally (i.t.) after s.c. tumor inoculation (solid tumor model). Here, mice initially received $2 \times 10^{7}$ CAR-T cells followed by weekly doses of $10^{7}$ CAR-T cells for two weeks (20-10-10 i.t., Figure 7).

In regimen one, transfer of $\mathrm{C} 4-27 \mathrm{z}$ and $\mathrm{C} 4 \mathrm{opt}-27 \mathrm{z}$ RNA CAR T cells by i.p. administration significantly attenuated the progression of disseminated human ovarian 

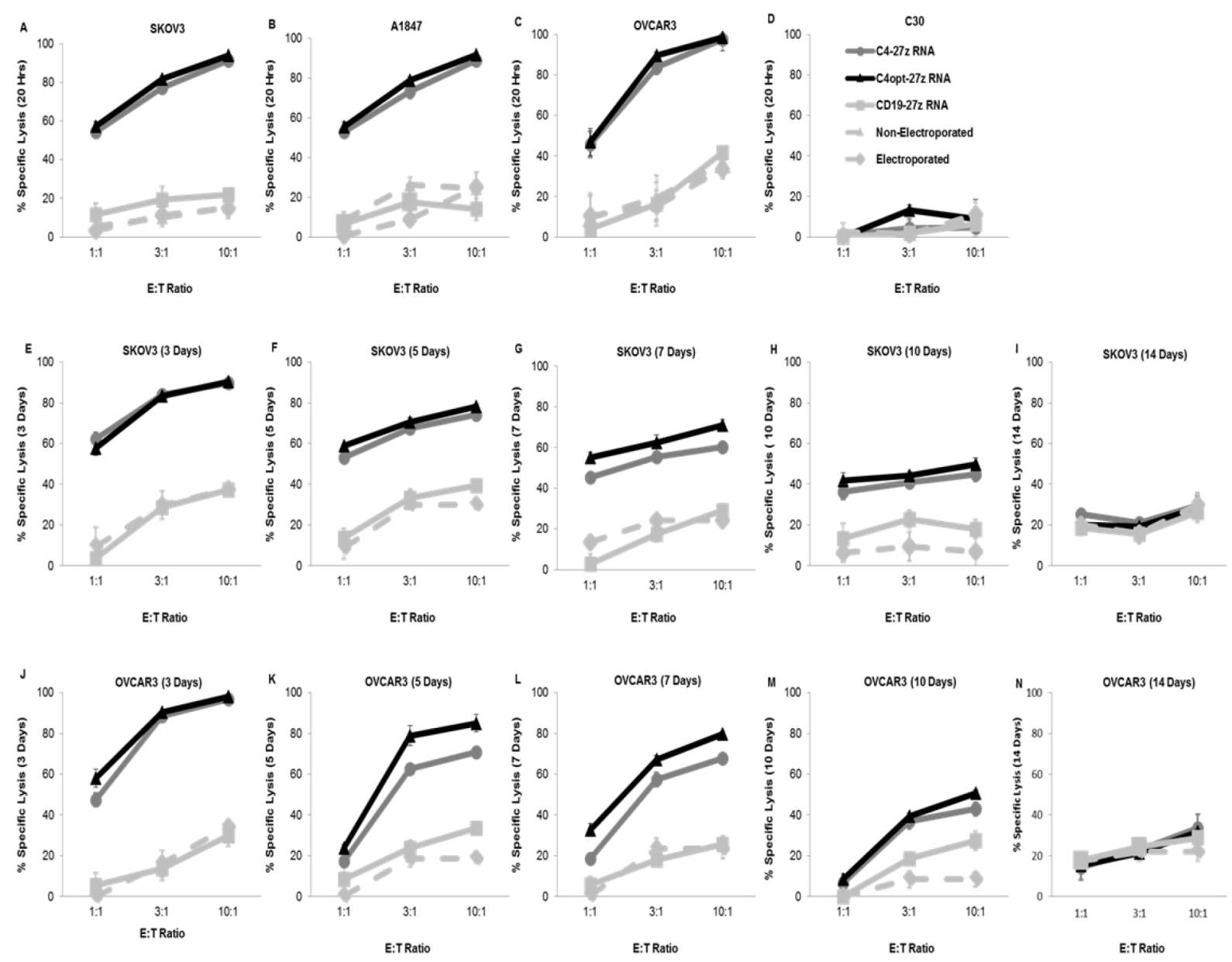

Figure 4: CAR-transfected, FRo-specific $\mathbf{T}$ cells show effective, time-dependent lytic function in a bioluminescent killing assay. A-D. $24 \mathrm{hr}$ after electroporation, C4-27z and C4opt-27z CAR T cells potently and specifically lyse FR $\alpha^{+}$SKOV3, A1847 and OVCAR3 but do not kill FR $\alpha^{-} \mathrm{C} 30$ cells at the indicated E/T ratios after coincubation with respective tumor cells. CD19-27z, electroporated T cells (containing no RNA) and non-electroporated T cells serve as negative controls. E-N. Killing potential of C4-27z and C4opt-27z RNA CAR T lymphocytes progressively declines during the 3, 5, 7, 10 or 14 d interval between RNA CAR electroporation and when cytolytic function in assessed. For all cytolytic assays, T cells are coincubated with tumor cells for $\sim 20 \mathrm{hr}$. Mean and SEM of six wells per data point is depicted.

cancer which grew rapidly in saline- and CD19-27z CAR-treated mice (Figures 5A-5B, two-way ANOVA, $p<.001$, D28). Similar to in vitro findings, C4opt-27z generally outperformed the parental C4-27z RNA CAR T cells in limiting tumor outgrowth. Initially, human $\mathrm{CD}^{+}$ and $\mathrm{CD}^{+} \mathrm{T}$ cells in $\mathrm{C} 4-27 \mathrm{z}$ and $\mathrm{C} 4$ opt-27z CAR cohorts were present in lower numbers in the peripheral circulation in comparison to CD19-27z CAR T cells, suggesting early FR $\alpha$-specific CAR $\mathrm{T}$ cell migration to specific tumor sites (Figure 5C, student $t$ test, $p<.01-.001$ ). Importantly, repeat administration of C4opt-27z CAR T cells resulted in significant expansion of $\mathrm{CD} 4^{+}$and $\mathrm{CD} 8^{+}$ $\mathrm{T}$ cells in peripheral blood (Figure 5D, $p<.001$ ), which correlated with the therapeutic efficacy of the C4opt-27z CAR. Although C4-27z and C4opt-27z CAR T cells were highly beneficial in this paradigm, we hypothesized that the 10-10-10 dosing regimen every third day was suboptimal as tumor growth progressed rapidly once therapy was completed. A similar dosing regimen was shown to be less than ideal in a mouse model of advanced leukemia, as spacing every 3 days did not give sufficient time for individual doses of RNA CAR T cells to complete their effects [19].

Given the drug-like kinetics of RNA CARs [17, 19] and based on our CAR expression data in vitro (Figure 1, Supplemental Figure 1), we predicted that a high loading dose $\left(2 \times 10^{7}\right)$ followed by lower maintenance doses $\left(10^{7}\right)$ at a longer interval of 7 days would result in greater efficacy. Indeed, this second regimen resulted in complete, durable tumor remission in $100 \%$ of $\mathrm{C} 4-27 \mathrm{z}$ and C4opt-27z RNA CAR T cell treated, tumor-bearing animals (Figures 6A-6B, $p<.001$, D28). Consistent with regimen one, $\mathrm{CD}^{+}$and $\mathrm{CD}^{+} \mathrm{C} 4$ opt-27z CAR T cells were first present at low numbers in peripheral circulation (Figure 6C). Likewise, successive administration of C4opt-27z CAR T cells resulted in more extensive CD4 ${ }^{+}$ and $\mathrm{CD}^{+} \mathrm{T}$ cell expansion in peripheral blood during the course of therapy (Figure 6D). 

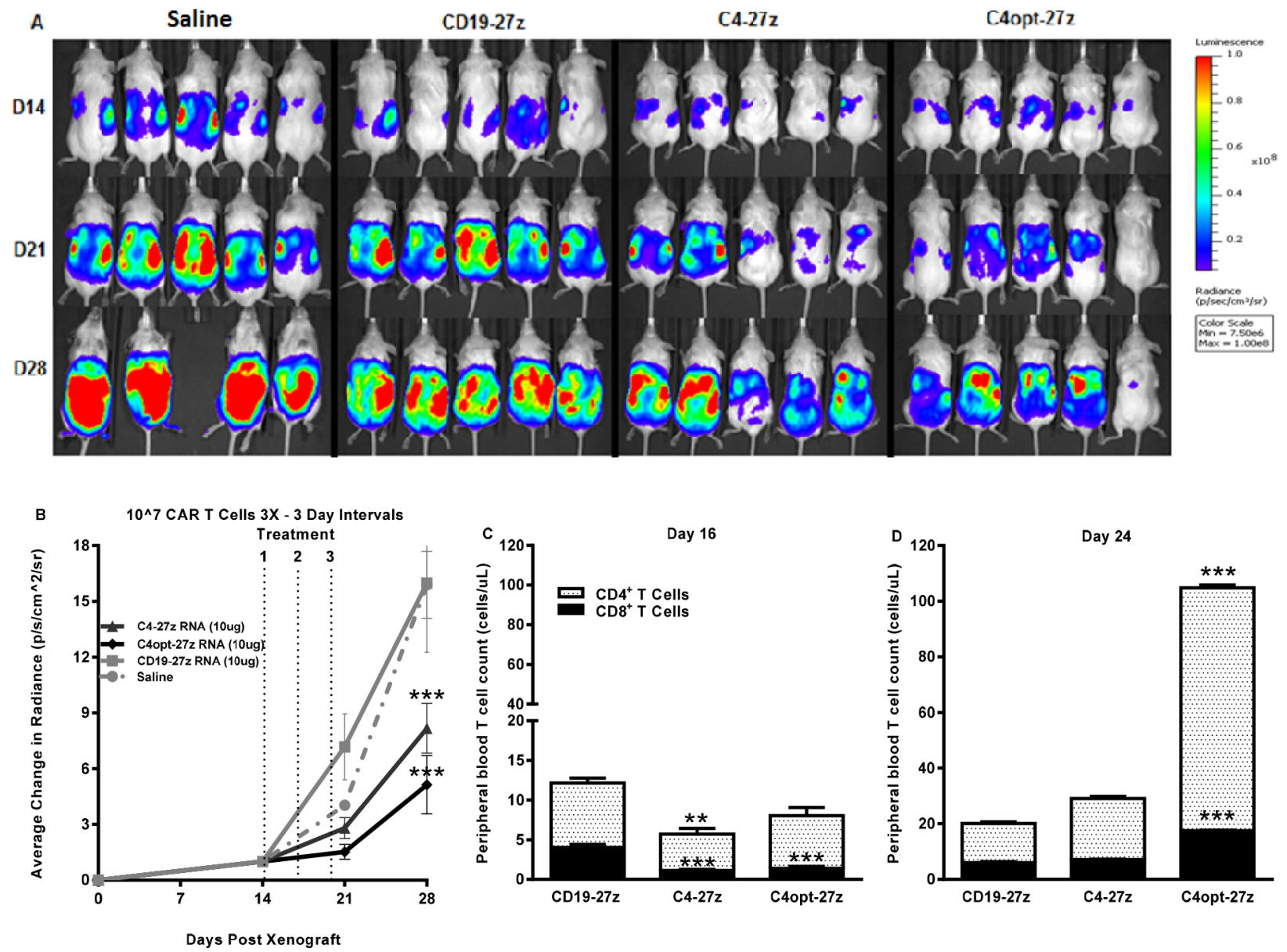

Figure 5: Human C4-27z and C4opt-27z RNA CAR $T$ cells reduce the progression of pre-established tumors in vivo. A. NSG mice bearing disseminated SKOV3 tumor were treated with intraperintoneal injections of $10^{7} \mathrm{CAR}^{+} \mathrm{T}$ cells on days 14, 17 and 20 and imaged weekly. B. Tumor growth was assessed by SKOV3 fLUC ${ }^{+}$bioluminescence, which revealed reduced tumor progression in animals receiving FR $\alpha$-specific $\mathrm{C} 4-27 \mathrm{z}$ or $\mathrm{C} 4$ opt-27z CAR T cell therapy (2-way ANOVA, $p<.001)$. C. CD4 ${ }^{+}$and $\mathrm{CD} 8^{+}$ C4-27z and C4opt-27z CAR T cells were largely absent from peripheral circulation in comparison to CD19-27z CAR T cells, suggesting FR $\alpha$-specific migration to tumor sites (student $t$ test, $p<.01-p<.001$ ). D. Repeat administration of C4opt-27z CAR T cells resulted in significant expansion of $\mathrm{CD}^{+}$and $\mathrm{CD}^{+} \mathrm{T}$ cells in peripheral blood, which correlated with therapeutic efficacy of the C4opt-27z CAR $(p<.001) . \mathrm{CD}^{+}$and $\mathrm{CD} 8^{+}$cells were quantitated from blood using the TruCount method. Mean cell concentration $($cells $/ \mu 1)+/-\mathrm{SEM}$ for all mice in each treatment group is shown.

Encouraged by the therapeutic potential of C4opt-27z CAR $T$ cells using the 20-10-10 weekly dosing regimen, we next tested the efficacy of C4opt-27z RNA CAR T cells against solid tumor, using a s.c. tumor model where RNA CAR therapies, in general, have been only partially effective against different tumor types ([43] and unpublished observations). Importantly, C4-27z and C4opt-27z CAR T cells significantly reduced the rate of solid tumor progression, although the majority of animals did not achieve complete remission (Figures $7 \mathrm{~A}-7 \mathrm{C}$, $p<.001$, D42). Paralleling the results in i.p. animal experiments, $\mathrm{CD}^{+}{ }^{+}$and $\mathrm{CD} 8^{+} \mathrm{C} 4 \mathrm{opt}-27 \mathrm{z}$ CAR T cells were initially present at low numbers in peripheral circulation compared to control CD19-27z CAR T cells (Figure $7 \mathrm{D}, p<.001$ ) and successive administration of C4opt-27z and C4opt-27z CAR T cells resulted in significant $\mathrm{CD}^{+}$and $\mathrm{CD} 8^{+} \mathrm{T}$ cell expansion in peripheral blood during the course of therapy (Figure 7E) ( $p<.05-$ $p<.001$ ). Notably, human T cells in the C4-27z and C4opt$27 z$ CAR cohorts continued to persist despite losing CAR reactivity (Figure 7F) (student $t$ test, $p<.05-.01$ ). Again, the antitumor potency of C4opt-27z was modestly increased relative to the $\mathrm{C} 4-27 \mathrm{z}$ CAR, albeit not to a level of statistical significance.

\section{DISCUSSION}

Given the elevated expression of FR $\alpha$ in various human malignancies [32-38], we sought to determine the therapeutic potential of RNA electroporated, FR $\alpha$-specific C4opt-27z RNA CAR T lymphocytes for the treatment of human cancer. With advances in gene transfer technology, cell cultivation and basic $\mathrm{T}$ cell biology, CAR T-cell therapy is becoming more potent, with improved results 
a

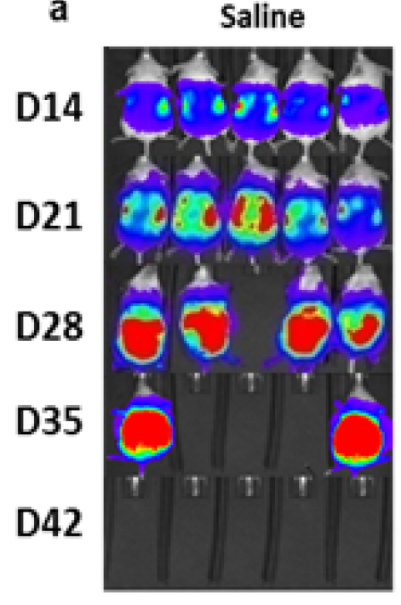

C4-27z RNA

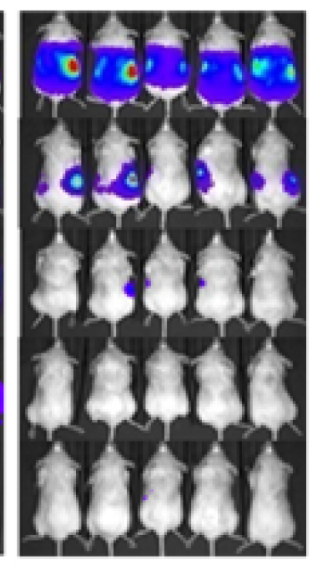

C4opt-27z RNA

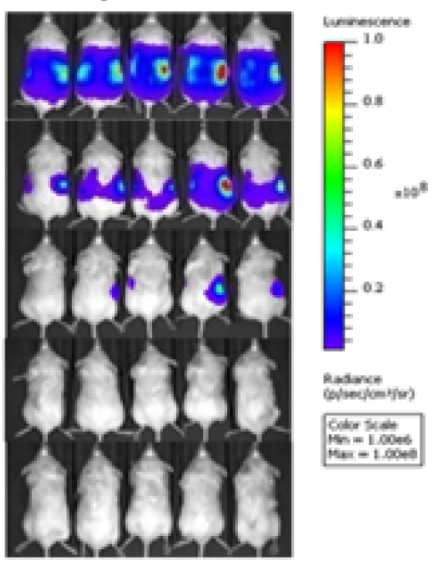

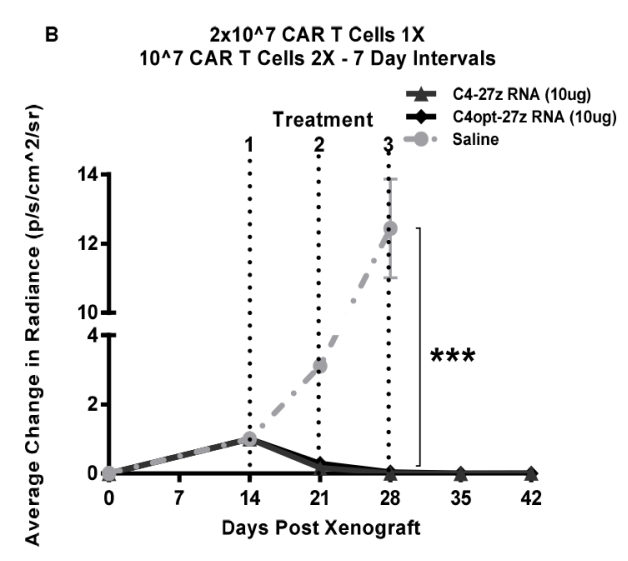
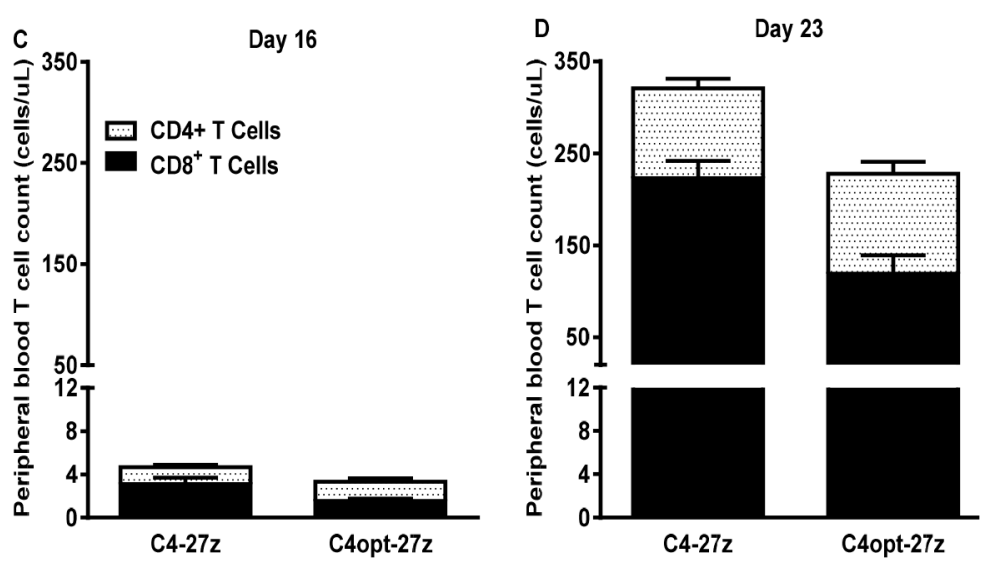

Figure 6: C4-27z and C4opt-27z RNA CAR T cells completely eliminate widely disseminated tumors in vivo. A. NSG mice bearing disseminated SKOV3 tumor were treated with one intraperintoneal injection of $2 \times 10^{7} \mathrm{CAR}^{+} \mathrm{T}$ cells on day 14 (loading dose) followed by a lower maintenance dose of $10^{7} \mathrm{CAR}^{+} \mathrm{T}$ cells on days 21 and 28 . B. Tumor growth was assessed by SKOV3 fLUC bioluminescence, which demonstrates complete tumor remission in all C4-27z and C4opt-27z CAR T lymphocyte treated, tumor-bearing animals (2-way ANOVA, $p<.001$ ). C. $\mathrm{CD}^{+}$and $\mathrm{CD}^{+} \mathrm{C} 4-27 \mathrm{z}$ and $\mathrm{C} 4 \mathrm{opt}-27 \mathrm{z}$ CAR T cells were initially present at low numbers in peripheral circulation, suggesting FR $\alpha$-specific CAR T cell migration to specific tumor locales. D-E. Conversely, successive administration of $\mathrm{C} 4-27 \mathrm{z}$ and $\mathrm{C} 4 \mathrm{opt}-27 \mathrm{z}$ CAR $\mathrm{T}$ cells resulted in extensive $\mathrm{CD}^{+}$and $\mathrm{CD}^{+} \mathrm{T}$ cell proliferation in peripheral blood during the course of therapy.

in clinical trials and increased awareness for the potential of immune toxicity [5-8, 30, 49-53]. Virally transduced CAR T cells possessing one or more costimulatory domains have displayed enhanced antitumor function and persistence in animal models and in the clinic [9-11, 23-27, 29, 30, 54]. However, lentiviral and retroviral CAR $\mathrm{T}$ lymphocyte therapies incorporating various costimulatory molecules that were administered to patients have in some cases resulted in amplified cytokine release, 'septic shock' and mortality [5, 6, 54-56]. In addition, viral gene transfer poses possible risks associated with stable integration, including the possibility of malignant $\mathrm{T}$ cell transformation, though rarely if ever seen, and cumulative off-tumor toxicity due to continued CAR T cell persistence $[57,58]$. Conversely, RNA CARs are non-integrating and transiently expressed, and injections of RNA CAR T cells can be quickly discontinued if necessary and toxicity is expected to progressively abate, because, as we show here, CAR T cell surface expression, cytokine release and lytic function gradually decline with time, particularly following CAR activation.

In the limited number of normal tissues in which the $\alpha$ isoform of folate receptor (FR) is expressed, the receptor is restricted to apical (luminal) surfaces, where it is inaccessible via the circulation [39]. Low-level FR $\alpha$ expression is present in the lung, kidney, intestines, heart and choroid plexus, although these folate receptors remain inaccessible to folate or folate-conjugates because of their distinct localization on the apical surfaces of polarized epithelium [39, 59-63]. In healthy patients, folate conjugate uptake has been limited to the kidneys where folate salvage occurs, and renal toxicity has not been observed with folate-chemotherapeutic agents, antibodies or directed T cells [44, 64-66]. However, acute toxicities accompanying administration of anti-folates, including methotrexate, need to be considered, though their mode 

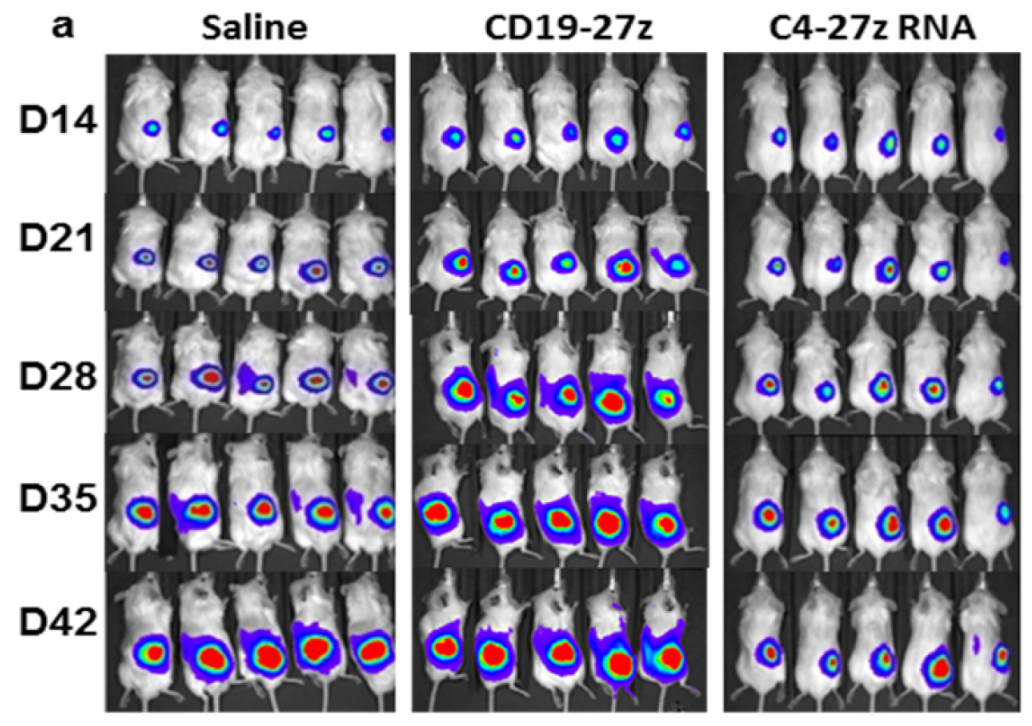

C4opt-27z RNA

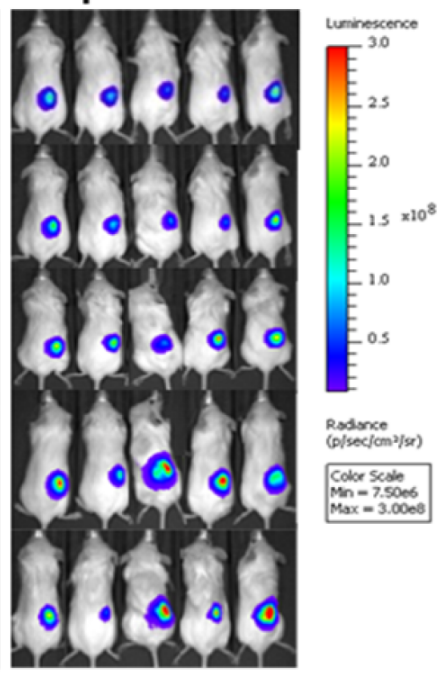

B
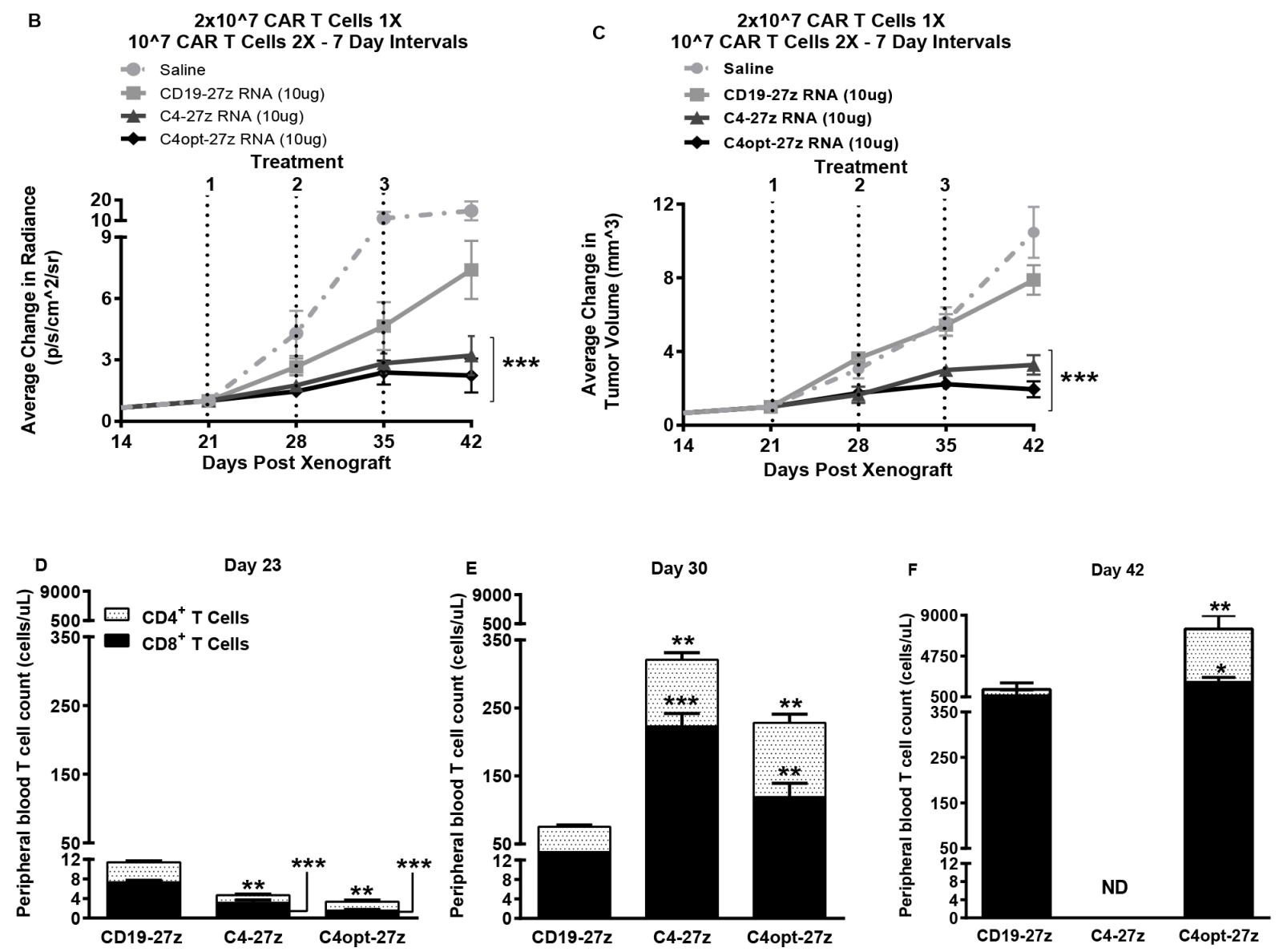

Figure 7: C4-27z and C4opt-27z RNA CAR T cells reduce the progression of solid ovarian cancer in vivo. A. NSG mice bearing solid SKOV3 tumor were treated with on intratumuoral injection of $2 \times 10^{7} \mathrm{CAR}+\mathrm{T}$ cells on day 21 (loading dose) followed by a lower maintenance dose of $10^{7} \mathrm{CAR}+\mathrm{T}$ cells on days 28 and 35 . B-C. Tumor growth was measured weekly by SKOV3 fLUC ${ }^{+}$ bioluminescence (B) and by caliper measurement. C4-27z and C4opt-27z CAR T lymphocytes treated significantly reduced tumor bioluminescence and volume compared to animals receiving no treatment (2-way ANOVA, $p<.001$ ). D. CD4 ${ }^{+}$and CD8 ${ }^{+} \mathrm{C} 4-27 \mathrm{z}$ and C4opt-27z CAR T cells were initially present at low numbers in peripheral circulation, suggesting FR $\alpha$-specific CAR T cell migration to specific tumor locales (student $t$ test, $p<.01-.001$ ). E. Repeat administration of C4-27z and C4opt-27z CAR T cells resulted in CD4 ${ }^{+}$ and $\mathrm{CD}^{+} \mathrm{T}$ cell expansion in peripheral blood during therapy (student $t$ test, $p<.01-.001$ ) F. C4-27z and C4opt-27z CAR T cells are not eliminated after treatment and continue to proliferate despite losing CAR reactivity (student $t$ test, $p<.05-.01$ ). 
of toxicity is not well understood. In the current study, assessment of the risk for acute toxicity in vivo stemming from C4 FR $\alpha$-specific RNA CAR T cell therapy is not possible since the $\mathrm{C} 4 \mathrm{CAR}$ recognizes human $\mathrm{FR} \alpha$, but not mouse FR $\alpha$. However, the C4 CAR has a reduced potential to recognize normal tissue bearing low levels of FR $\alpha$ likely due, in part, to its moderate functional avidity when expressed on the $\mathrm{T}$ cell surface following lentivirus transduction [67], suggesting that effective therapy can occur in the absence of significant toxicity. Rapid onset toxicity has been reported elsewhere in a lymphodepleted patient following administration of high numbers of autologous $T$ cells engineered with retrovirus to express HER-2/ErbB2-specific CAR [6]. Despite this, numerous studies of immunogenic folate agents in animals and phase I clinical trials have demonstrated both safety and efficacy of FR targeting [66, 68-70], and an early phase I clinical study using first generation $\mathrm{FR} \alpha$-specific T cells (without a costimulatory domain in the CAR construct) demonstrated that large numbers of these cells can be safety administered to patients without acute toxicity [44]. In another study, intraperitoneal administration of autologous $\mathrm{T}$ cells armed with a FR $\alpha$-specific bispecific antibody to ovarian cancer patients resulted in a $27 \%$ intraperitoneal response rate with no on-target toxicities reported [66]. Collectively, these data suggest that a therapeutic window exists wherein effective therapy can be applied in the absence of overt toxicity against normal tissues. However, given that RNA CARs do possess the potential to mediate acute toxicity immediately after infusion; administration of steroids or cyclophosphamide, a $\mathrm{T}$ cell lymphodepleting agent [19], may be considered to more rapidly detune or abate FR $\alpha$-specific RNA CAR T cells in vivo.

While unlikely, there exists the potential for FR $\alpha$ specific RNA CAR T cell toxicity in patients resulting from the need for multiple injections. For example, anaphylaxis as a byproduct of transgene immunogenicity may occur if repeated infusions are given over extended periods of time without lymphodepleting pre-conditioning during or after immunotherapy. In this line, multiple infusions of mesothelin-specific RNA CAR T cells were reported to lead to clinical anaphylaxis in a single patient, although the mechanism was believed to involve $\operatorname{IgE}$ antibodies specific to the murine CAR utilized rather than off-tissue effects from targeting FR $\alpha$ mesothelin [71]. Hence, RNA CARs derived from murine antibodies may present safety concerns for use in humans, especially when administered utilizing an extended dosing schedule. To specifically address this, C4opt-27z RNA CAR was fully humanized and infusion schedules were optimized in order to treat over a brief, 3 week period.

To further the potential safety of C4-27z RNA CAR $\mathrm{T}$ cell therapy, we codon optimized C4-27z CAR and removed ORFs, creating a novel CAR (C4opt-27z) with reduced likelihood of generating off-target transcription products which could potentially harm individuals or provoke immune rejection of the engineered $\mathrm{T}$ cell. Importantly, optimization of $\mathrm{C} 4-27 \mathrm{z}$ CAR did not negatively impact antitumor efficacy in any of our experiments. Conversely, when compared to $\mathrm{C} 4-27 \mathrm{z}$ CAR, C4opt-27z CAR displays moderately enhanced antitumor activity in vitro and enhanced effector function in vivo. C4opt-27z also exhibits greater transcriptional efficiency in vitro, potentially leading to the production of significantly higher yields of therapeutic RNA at lower cost (Supplemental Figure 9). Hence, C4opt-27z CAR may be superior to $\mathrm{C} 4-27 \mathrm{z}$ CAR in terms of clinical application.

RNA CAR methods may permit rapid iterative changes in CAR design and the possibility of moving toward a good manufacturing practice (GMP)compliant system with potentially lower expenses and less complicated pharmacokinetic testing as opposed to lentiviral or retroviral CARs which can persist for extended periods $[17,19]$. Using an RNA approach, we have generated several additional RNA-based CARs at low cost which are currently being screened for potency (Powell and Schutsky, unpublished observations, 2014). As evaluated here, candidate RNA CARs, such as C4opt-27z, demonstrating strong efficacy in vitro and in preclinical models may be selected for rapid conversion to viral CARs, as warranted.

Our experiments unequivocally demonstrate that C4opt-27z RNA CAR T lymphocytes have substantial treatment value using a multiple, weighted dosing strategy in aggressive ovarian cancer models. These studies are novel in that they provide the first evidence that FR $\alpha$-specific, CD27-costimulated, redirected RNA CAR $T$ cells can have potent and enduring antitumor effects in vivo without the use of an integrating viral vector system. Immunoreactivity, cytolytic potential and antitumor function of C4opt-27z RNA CAR T cells in our experiments is striking, and begins to rival that of reported virally modified FR $\alpha$-specific CAR T lymphocytes in other paradigms [28]. However, the benefits of using C4opt-27z RNA CAR T cells against solid tumor, while highly significant, were less dramatic and mimic those reported with HER-2/ErbB2-specific RNA CAR T cells against solid ovarian cancer [43].

In general, FR $\alpha$-specific RNA CAR T cell therapy is unique because it has the potential to be applied to numerous cancers which express the antigen to differing extents. C4opt-27z redirected T lymphocytes are highly reactive against multiple ovarian cancer lines displaying disparate levels of FR $\alpha$ expression. Our therapy also appears to be highly effective for eradicating other types of cancers which express varying levels of FR $\alpha$, including breast and pancreatic cancers expressing WT and/or mutant BRCA1 and/or BRCA2 (Schutsky and Powell, 2014, unpublished observations). 
Given the temporary, drug-like kinetics of RNA CARs, it not surprising that a loading dose $\left(2 \times 10^{7}\right)$ followed by lower maintenance doses $\left(10^{7}\right.$ or $\left.5 \times 10^{6}\right)$ at an appropriate half-life interval ( 7 days) results in improved $\mathrm{T}$ cell proliferation and antitumor function as opposed to closer spacing ( $10^{7}$ every 3 days), which may not allow for sufficient time for $\mathrm{T}$ cells to complete their effects. Others have reported that weekly, weighted dosing as opposed to equal dosing every $3^{\text {rd }}$ day is more effective in treating disseminated leukemia [19]. Although not examined in our experiments, treatment intervals lasting longer than 7 days may allow for xenograft harbor sites to recover and re-seed, making relapse possible [19].

Based on our imaging studies in vivo, maximal effects appear to occur within 3-5 days of each administration, with the first administration having the most substantial impact. Notably, RNA CAR T cell expression declines more rapidly in vivo than in vitro, likely because RNA CAR T cells in immune replete, tumor-bearing mice encounter antigen and homeostatic queues that promote $\mathrm{T}$ cell activation, proliferation and RNA metabolism. A total of three doses employed in these studies was a pragmatic decision based on numbers of available T cells using our non-clinical scale manufacturing. It is possible that administering a larger number of T-cell infusions or administering greater numbers of $\mathrm{T}$ cells during each infusion might increase the number of animals achieving complete remission, particularly in the solid tumor model which appears more difficult to treat. Conversely, repeat injections of exorbitant numbers of T cells over extended periods could promote the development of cumulative off-target toxicity not otherwise observed under single dosing. Alternatively, a combination of multiple CAR $\mathrm{T}$ cell infusions with "erasure" of the prior infused cells using lymphodepletion may allow for optimal efficacy of each cell infusion or reduce the total number of infusions required for complete response, as is the case for particular CARs against disseminated leukemia [19]. Notably, the majority of animals in our models did not succumb to cancer, but rather GVHD, in the very late phase of therapy ( $\sim 50$ days after first $T$ cell dose) that was likely triggered by xenogeneic responses of human $T$ cells against mouse tissue and the absence of suicide induction systems in NSG animals to effectively eliminate CAR-negative T cells after therapy termination.

Furthermore, it is unclear whether certain costimulatory domains might provide greater benefit in RNA-based CAR T cell therapy. It has been suggested that CAR costimulatory domains carry less influence in RNA models than for viral models, and that cell dose, interval, $\mathrm{T}$ lymphocyte age, and lymphodepletion may be critical factors for successful RNA CAR therapy $[17,19]$. Still, studies have not rigorously compared RNA CARs containing one or more costimulatory molecules to determine which domains, if any, provide the greatest efficacy. In addition, defining the specific
T-cell populations that may be most effectively modified with RNA CARs remains to be determined although our initial results suggest that modifying total $\mathrm{CD}^{+}$ $\mathrm{T}$ cells would probably provide more benefit than $\mathrm{CD}^{+} \mathrm{T}$ or $\mathrm{CD}^{+} \mathrm{T}$ cells alone, especially if utilized for in vivo application, based on a greater proinflammatory response and heightened lytic function when both CAR $\mathrm{T}$ cell populations are combined. In addition, the $\mathrm{T}$ cells utilized for these studies likely contain Tregs, which upon activation with C4opt RNA, could reduce the effectiveness of effector $\mathrm{T}$ lymphocytes, as both Tregs and effector $\mathrm{T}$ cells would be expected to migrate to FR $\alpha$-specific tumor locales. Nevertheless, antitumor responses ensued both in vitro and in vivo.

Despite its strengths, potential limitations of RNA CAR therapy do exist, such as transient CAR expression, the potential need for large ex vivo expansion to administer multiple injections, limited proliferation in vivo (compared to viral methods) and lack of durable CAR-based antitumor memory cells. In addition, recent safety concerns, including the induction of anaphylactic responses due to the immunogenic nature of multi-dose murine-based CAR regimens need to be addressed [48]. C4-27z CAR constructs are expected to circumvent this issue via incorporation of only human components within the CAR vector. Our experiments also demonstrate that very high amounts of RNA electroporated into $\mathrm{T}$ lymphocytes can cause significant antigen-independent activation, including cytokine production and cytolysis. Importantly, such experiments further suggest that appropriate levels of RNA for electroporation can be identified that reduce antigen independent activation effects in order to minimize the potential for adverse events.

In conclusion, RNA CAR T cell therapy, optimized by rigorous preclinical testing as described here, has obvious safety benefits of a non-integrating, transient CAR expression platform and will continue to complement current therapies being developed with retroviral and lentiviral CARs, and, in certain circumstances, may be used as primary therapy. Our results reveal the efficacy of an optimized FR $\alpha$-specific, CD27 costimulated RNA CAR $\mathrm{T}$ cell therapy platform and thus advocate for expedited clinical application of C4opt-27z CAR T cells across the broad range of $\mathrm{FR} \alpha$-expressing cancers.

\section{MATERIALS AND METHODS}

\section{Construction of in vitro transcription (IVT) vectors and RNA electroporation}

A lentiviral vector encoding MOv19 anti-FR $\alpha$ scFV coupled with a cytosolic tail comprised of a CD27 costimulatory domain had been previously engineered [28]. A novel, fully human scFV against FR $\alpha$ (C4) was utilized for CAR construction [47]. MOv19 was removed and 
C4 scFV "swapped" in to create a fully humanized CAR construct, C4-27z (Figure 1A). To generate C4opt-27z, internal ORFs were removed from the C4-27z CAR (Life Technologies, GeneArt, Grand Island, NY) and all codons were optimized, reducing the possibility of undesirable transcription products, increasing translational efficiency and reducing the costs of producing RNA (Supplemental Figures $8 \mathrm{~A}-8 \mathrm{~B})$. C4-27z or C4opt-27z CAR constructs were then subcloned into a pD-A.lenti cloning site.2bg. $150 \mathrm{~A}$ vector (PDA) that had been optimized for $\mathrm{T}$ cell transfection, CAR expression and RNA production $[17,30]$. A similar approach was used to subclone a control CAR, CD19-27z, which does not target FR $\alpha^{-}$but CD19+ cancer cells [17-19].

C4-27z, C4opt-27z and CD19-27z CAR cDNAs were confirmed by direct sequencing and linearized by SpeI digestion prior to RNA IVT. The T7 mScript Standard mRNA Production System (Cellscript, Inc., Madison, WI) was utilized to generate capped/tailed IVT RNA. The IVT RNA was purified by phenol-chloroform extraction followed by RNeasy Mini Kit (Qiagen, Inc., Valencia, CA). Purified RNA was eluted in RNase-free water at $1-2 \mathrm{mg} / \mathrm{ml}$ and stored at $-80^{\circ} \mathrm{C}$ until use. RNA integrity was confirmed by $260 / 280$ absorbance and visually on an RNA denaturing gel.

\section{Human T cells}

Primary human T cells were isolated from healthy volunteer donors after leukapheresis and purchased from the Human Immunology Core at the University of Pennsylvania. All specimens were collected under a protocol approved by a University Institutional Review Board, and written informed consent was obtained from each donor. T cells were cultured in complete media (RMPI 1640 supplemented with 10\% heat-inactivated FBS, $100 \mathrm{U} / \mathrm{mL}$ penicillin, $100 \mathrm{ug} / \mathrm{mL}$ streptomycin sulfate, $10 \mathrm{mM} \mathrm{HEPES)}$ and stimulated with antiCD3 and anti-CD28 mAbs-coated beads (Invitrogen) as described [72]. Human recombinant interleukin-2 (IL-2; Novartis) was added one day after CD3/CD8 stimulation, then every other day at 50-100 IU/mL final concentration, for 14 days, until $\mathrm{T}$ cell number reached approximately $5 \times 10^{8}$ cells. At approximately 14 days, T cells became "rested down," as determined by both decreased growth kinetics and cell sizing using the Multisizer 3 Coulter Counter (Beckman Coulter). T cells were washed twice with Opti-Mem and suspended in Opti-Mem at a final concentration of $10^{8} / \mathrm{mL}$ prior to electroporation. Subsequently, T cells were mixed with $10 \mu \mathrm{g}$ IVT RNA/0.1 mL T cells and electroporated in a 2-mm cuvette (Biorad) using an ECM830 Electro Square Wave Porator (Harvard Apparatus, BTX, Hollison, MA) at $500 \mathrm{~V}, 700 \mathrm{usec}, 1$ pulse. Viability post transfection ranged from $65-85 \%$. Viable $\mathrm{T}$ cells used for experiments had 95-100\% CAR expression at the time of use, except in experiments where time-dependent effects were assessed.

\section{Cell lines}

Cell lines used in immune based assays include the established human ovarian cancer cell lines SKOV3, A1847, OVCAR3, A2780 and C30. For cell lysis assays, target cancer cell lines were transduced to express firefly luciferase $\left(\mathrm{fLuc}^{+}\right)$. For specificity controls, the mouse malignant mesothelioma cell line, AE17 (provided by Steven Albelda, University of Pennsylvania), was transduced with lentivirus to express FR $\alpha$ (AE17.FR $\alpha$ ). K562 and CD19-expressing K562 (K562.CD19), human erythroleukemic control cell lines, were provided by Michael Milone of the University of Pennsylvania. All tumor lines were maintained in RPMI-1640 (Invitrogen) supplemented with $10 \% \quad(\mathrm{v} / \mathrm{v})$ heat-inactivated FBS, $2 \mathrm{mM}$ L-glutamine, $100 \mu \mathrm{g} / \mathrm{mL}$ penicillin and $100 \mathrm{U} / \mathrm{mL}$ streptomycin. Cell lines were routinely tested for mycoplasma contamination.

\section{Flow cytometric analysis}

The following mAbs were used for phenotypic analysis: i. biotin-SP-conjugated AffiniPure rabbit antihuman $\operatorname{IgG}(\mathrm{H}+\mathrm{L})$ and ii. biotin-SP-conjugated AffiniPure rabbit anti-mouse $\operatorname{IgG}(\mathrm{H}+\mathrm{L})$ (Jackson, West Grove, PA); iii. biotin-conjugated recombinant human FOLR1 (RD Systems, Minneapolis, MN / Thermo Scientific, Rockford, IL); i.v. streptavidin-APC (BD, San Jose, CA); v. BD ViaProbe (7-AAD); vii. anti-human CD3-FITC, anti-human CD4-FITC, anti-human CD8-FITC (eBioscience). In adoptive immunotherapy experiments, $\mathrm{T}$ cells from peripheral blood were obtained via retroorbital bleeding and stained for the presence of human CD45, CD3 and CD8 using anti-human CD45-PE, antihuman CD3-PerCP/Cy5.5 and anti-human CD8-APC (Biolegend, San Diego, CA). After gating on the human $\mathrm{CD} 45^{+}$population, the $\mathrm{CD}^{+}$and $\mathrm{CD}^{+}$subsets were quantified using TruCount tubes (BD Biosciences) with known numbers of fluorescent beads as described in the manufacturer's instructions. Tumor cell surface expression of FR was detected by Mov18/ZEL antibody (Enzo Life Sciences). Flow samples were run using BD FACS Canto and cytometric data analyzed by FlowJo 7.6.5 software.

\section{Cytokine release assays}

Cytokine release assays were performed by co-culture of $10^{5} \mathrm{~T}$ cells with $10^{5}$ target cells per well in 96-well round bottom plates in a final volume of $200 \mathrm{ul}$ of RPMI complete media. After $\sim 24 \mathrm{hrs,} \mathrm{supernatants} \mathrm{were}$ assayed for presence of IFN- $\gamma$ and IL-2 using ELISAs, according to manufacturer's instructions (Biolegend). IFN- $\gamma$, IL-2, IL-4, IL-10, MIP-1A and TNF- $\alpha$ cytokines were measured by flow cytometry with Cytometric Bead Array (BD Biosciences), based on protocols from the manufacturer. All cytokine data are represented as a mean of triplicate wells +/- SEM. 


\section{Cytotoxicity assays}

For cell-based bioluminescence assays, $3 \times 10^{4}$ firefly Luciferase expressing (fLuc + ) tumor cells were cultured in complete RMPI media in the presence of different ratios of RNA transfected CAR T cells in a 96-well Microplate (BD Biosciences). After incubation for $\sim 20 \mathrm{hr}$ at $37^{\circ} \mathrm{C}, 100 \mu \mathrm{l}$ media was removed from each well and bioluminescence was assessed using the Tropix Luc-Screen Assay (Applied Biosystems, Bedford, MA), according to manufacturer's instructions. Percent tumor cell viability was calculated as the mean luminescence of the experimental sample divided by the mean luminescence of the input number of target cells utilized in the assay times 100 . All cytolytic data are represented as a mean of six wells $+/-$ SEM.

\section{Xenograft models of ovarian cancer}

Animals were obtained from the Stem Cell and Xenograft Core of the Abramson Cancer Center, University of Pennsylvania. 12- to 20-week-old nonobese diabetic/ severe combined immunodeficient $/ \gamma$-chain ${ }^{-/}$(NSG) mice were bred, treated, and maintained under pathogen-free conditions in-house under University of Pennsylvania Institutional Animal Care and Use Committee-approved protocols. NSG mice were inoculated either intraperitoneally (i.p.) or subcutaneously (s.c.) with $5 \times 10^{6}$ SKOV3 $\mathrm{fLuc}^{+}$ cells in the abdomen or flank on day 0 . For each experiment, five mice were randomized per group before treatment. In both i.p. models, tumors were widely disseminated at 14 days, as measured by bioluminescence imaging. In the s.c. model, tumors were detectable by imaging at 14 days, becoming physically palpable by 21 days. 13 or 20 days after tumor inoculation, human primary $\mathrm{T}$ leukocytes were electroporated with C4-27z, C4opt-27z or CD19-27z CAR RNA, then recovered in RPMI media containing with 50-100 IU/ml IL-2 until injection the following day. In the initial i.p. model, mice were injected with $10^{7} \mathrm{CAR}-\mathrm{T}$ cells every 3 days for 9 days, beginning at day 14 (10-10-10 i.p.). In subsequent experiments, rodents were administered $2 \times 10^{7}$ CAR-T cells on day 14 followed by one weekly dose of $10^{7}$ CAR-T cells for two weeks (20-10-10 i.p.). The solid tumor model was similar to the second i.p. model, except that tumor inoculation was subcutaneous and treatment was delivered intratumorally (i.t.). Additional control groups of i.p. and i.t. animals received either saline injections or T cells containing no RNA (see Supplemental Figures 9A-9C for schedules). Each in vivo experiment was repeated at least twice with similar results. Tumor dimensions were measured with calipers (s.c.) and tumor volumes calculated with the following formula: $V=1 / 2\left(\right.$ length $\times$ width $^{2}$ ), where length is greatest longitudinal diameter and width is greatest transverse diameter. Animals were imaged before T-cell transfer and every week thereafter.

\section{Bioluminescence imaging}

Imaging of tumor was performed with the Xenogen IVIS imaging system and the photons emitted from fLuc ${ }^{+}$ cells within the animal body were quantified with the Living Image Version 3.0 software (Xenogen). In brief, mice bearing $\mathrm{fLuc}^{+} \mathrm{SKOV} 3$ tumor cells were injected intraperitoneally with D-luciferin $(150 \mathrm{mg} / \mathrm{kg}$ stock, $100 \mu \mathrm{l}$ of D-luciferin per $10 \mathrm{~g}$ of mouse body weight) suspended in PBS, and imaged under isoflurane anesthesia after $\sim 10$ minutes. Pseudocolor images representing light intensity (blue, least intense; red, most intense) were generated with Living Image. Imaging findings were confirmed at necropsy.

\section{Statistical analysis}

The data are reported as means +/- SEM. Statistical analysis was performed by the use of 2-way ANOVA for the tumor burden (tumor volume, photon counts). Student $t$ test was used to evaluate differences in CAR expression or T cell number in peripheral blood. GraphPad Prism 5.0 (GraphPad Software) was utilized for the statistical calculations. $P<.05$ was considered significant.

\section{ACKNOWLEDGMENTS}

The authors thank the Bethesda Foundation for their generous gift and Drs. Steven Albelda and Michael Malone of the University of Pennsylvania for donating specific cell lines used in the studies, Stephen Santoro for technical advice and Thomas Gallabrant for assistance with flow cytometry.

\section{CONFLICTS OF INTEREST}

D.J.P. and Y.Z. have patent applications in some of the technology described in this article. All other authors have no conflict of interest.

\section{GRANT SUPPORT}

This work was supported by grants from the Basser Research Center for BRCA, the Ovarian Cancer Research Fund, the Sandy Rollman Ovarian Cancer Foundation, the NIH (RO1-CA168900), the Bethesda Foundation and research funding provided through an alliance between Novartis and the University of Pennsylvania.

\section{REFERENCES}

1. Costello E, Munoz M, Buetti E, Meylan PR, Diggelmann H, Thali M. Gene transfer into stimulated and unstimulated T lymphocytes by HIV-1-derived lentiviral vectors. Gene therapy. 2000; 7:596-604. 
2. Rudoll T, Phillips K, Lee SW, Hull S, Gaspar O, Sucgang N, Gilboa E, Smith C. High-efficiency retroviral vector mediated gene transfer into human peripheral blood CD4+ T lymphocytes. Gene therapy. 1996; 3:695-705.

3. Zhao Y, Zheng Z, Cohen CJ, Gattinoni L, Palmer DC, Restifo NP, Rosenberg SA, Morgan RA. High-efficiency transfection of primary human and mouse $\mathrm{T}$ lymphocytes using RNA electroporation. Molecular therapy : the journal of the American Society of Gene Therapy. 2006; 13:151-159.

4. Ferber D. Gene therapy. Safer and virus-free? Science. 2001; 294:1638-1642.

5. Brentjens R, Yeh R, Bernal Y, Riviere I, Sadelain M. Treatment of chronic lymphocytic leukemia with genetically targeted autologous $\mathrm{T}$ cells: case report of an unforeseen adverse event in a phase I clinical trial. Molecular therapy: the journal of the American Society of Gene Therapy. 2010; 18:666-668.

6. Morgan RA, Yang JC, Kitano M, Dudley ME, Laurencot CM, Rosenberg SA. Case report of a serious adverse event following the administration of T cells transduced with a chimeric antigen receptor recognizing ERBB2. Molecular therapy : the journal of the American Society of Gene Therapy. 2010; 18:843-851.

7. Heslop HE. Safer CARS. Molecular therapy : the journal of the American Society of Gene Therapy. 2010; 18:661-662.

8. Buning H, Uckert W, Cichutek K, Hawkins RE, Abken H. Do CARs need a driver's license? Adoptive cell therapy with chimeric antigen receptor-redirected $\mathrm{T}$ cells has caused serious adverse events. Human gene therapy. 2010; 21:1039-1042.

9. Maher J, Brentjens RJ, Gunset G, Riviere I, Sadelain M. Human T-lymphocyte cytotoxicity and proliferation directed by a single chimeric TCRzeta /CD28 receptor. Nature biotechnology. 2002; 20:70-75.

10. Milone MC, Fish JD, Carpenito C, Carroll RG, Binder GK, Teachey D, Samanta M, Lakhal M, Gloss B, Danet-Desnoyers G, Campana D, Riley JL, Grupp SA, June $\mathrm{CH}$. Chimeric receptors containing CD137 signal transduction domains mediate enhanced survival of $\mathrm{T}$ cells and increased antileukemic efficacy in vivo. Mol Ther. 2009; 17:1453-1464.

11. Carpenito C, Milone MC, Hassan R, Simonet JC, Lakhal M, Suhoski MM, Varela-Rohena A, Haines KM, Heitjan DF, Albelda SM, Carroll RG, Riley JL, Pastan I, June CH. Control of large, established tumor xenografts with genetically retargeted human T cells containing CD28 and CD137 domains. Proceedings of the National Academy of Sciences of the United States of America. 2009; 106:3360-3365.

12. Bell MP, Huntoon CJ, Graham D, McKean DJ. The analysis of costimulatory receptor signaling cascades in normal $\mathrm{T}$ lymphocytes using in vitro gene transfer and reporter gene analysis. Nature medicine. 2001; 7:1155-1158.

13. Van Tendeloo VF, Willems R, Ponsaerts P, Lenjou M, Nijs G, Vanhove M, Muylaert P, Van Cauwelaert P, Van Broeckhoven C, Van Bockstaele DR, Berneman ZN.
High-level transgene expression in primary human $\mathrm{T}$ lymphocytes and adult bone marrow CD34+ cells via electroporation-mediated gene delivery. Gene therapy. 2000; 7:1431-1437.

14. Ebert O, Finke S, Salahi A, Herrmann M, Trojaneck B, Lefterova P, Wagner E, Kircheis R, Huhn D, Schriever F, Schmidt-Wolf IG. Lymphocyte apoptosis: induction by gene transfer techniques. Gene therapy. 1997; 4:296-302.

15. Cotten M, Saltik M. Intracellular delivery of lipopolysaccharide during DNA transfection activates a lipid A-dependent cell death response that can be prevented by polymyxin B. Human gene therapy. 1997; 8:555-561.

16. Sullenger BA, Gilboa E. Emerging clinical applications of RNA. Nature. 2002; 418:252-258.

17. Barrett DM, Zhao Y, Liu X, Jiang S, Carpenito C, Kalos M, Carroll RG, June CH, Grupp SA. Treatment of advanced leukemia in mice with mRNA engineered T cells. Human gene therapy. 2011; 22:1575-1586.

18. Zhao Y, Moon E, Carpenito C, Paulos CM, Liu X, Brennan AL, Chew A, Carroll RG, Scholler J, Levine BL, Albelda SM, June CH. Multiple injections of electroporated autologous $\mathrm{T}$ cells expressing a chimeric antigen receptor mediate regression of human disseminated tumor. Cancer research. 2010; 70:9053-9061.

19. Barrett DM, Liu X, Jiang S, June CH, Grupp SA, Zhao Y. Regimen-specific effects of RNA-modified chimeric antigen receptor $\mathrm{T}$ cells in mice with advanced leukemia. Human gene therapy. 2013; 24:717-727.

20. Rabinovich PM, Komarovskaya ME, Wrzesinski SH, Alderman JL, Budak-Alpdogan T, Karpikov A, Guo H, Flavell RA, Cheung NK, Weissman SM, Bahceci E. Chimeric receptor mRNA transfection as a tool to generate antineoplastic lymphocytes. Human gene therapy. 2009; 20:51-61.

21. Li L, Liu LN, Feller S, Allen C, Shivakumar R, Fratantoni J, Wolfraim LA, Fujisaki H, Campana D, Chopas N, Dzekunov S, Peshwa M. Expression of chimeric antigen receptors in natural killer cells with a regulatory-compliant non-viral method. Cancer gene therapy. 2010; 17:147-154.

22. Riet $\mathrm{T}$, Holzinger A, Dorrie J, Schaft N, Schuler G, Abken H. Nonviral RNA transfection to transiently modify $\mathrm{T}$ cells with chimeric antigen receptors for adoptive therapy. Methods in molecular biology. 2013; 969:187-201.

23. Finney HM, Akbar AN, Lawson AD. Activation of resting human primary $\mathrm{T}$ cells with chimeric receptors: costimulation from CD28, inducible costimulator, CD134, and CD137 in series with signals from the TCR zeta chain. Journal of immunology. 2004; 172:104-113.

24. Friedmann-Morvinski D, Bendavid A, Waks T, Schindler D, Eshhar Z. Redirected primary T cells harboring a chimeric receptor require costimulation for their antigen-specific activation. Blood. 2005; 105:3087-3093.

25. Imai C, Mihara K, Andreansky M, Nicholson IC, Pui CH, Geiger TL, Campana D. Chimeric receptors with 4-1BB 
signaling capacity provoke potent cytotoxicity against acute lymphoblastic leukemia. Leukemia. 2004; 18:676-684.

26. Moeller M, Haynes NM, Trapani JA, Teng MW, Jackson JT, Tanner JE, Cerutti L, Jane SM, Kershaw MH, Smyth MJ, Darcy PK. A functional role for CD28 costimulation in tumor recognition by single-chain receptormodified T cells. Cancer gene therapy. 2004; 11:371-379.

27. Pule MA, Straathof KC, Dotti G, Heslop HE, Rooney CM, Brenner MK. A chimeric T cell antigen receptor that augments cytokine release and supports clonal expansion of primary human T cells. Molecular therapy : the journal of the American Society of Gene Therapy. 2005; 12:933-941.

28. Song DG, Ye Q, Poussin M, Harms GM, Figini M, Powell DJ Jr. CD27 costimulation augments the survival and antitumor activity of redirected human $\mathrm{T}$ cells in vivo. Blood. 2012; 119:696-706.

29. Kochenderfer JN, Wilson WH, Janik JE, Dudley ME, Stetler-Stevenson M, Feldman SA, Maric I, Raffeld M, Nathan DA, Lanier BJ, Morgan RA, Rosenberg SA. Eradication of B-lineage cells and regression of lymphoma in a patient treated with autologous $\mathrm{T}$ cells genetically engineered to recognize CD19. Blood. 2010; 116:4099-4102.

30. Porter DL, Levine BL, Kalos M, Bagg A, June CH. Chimeric antigen receptor-modified $\mathrm{T}$ cells in chronic lymphoid leukemia. The New England journal of medicine. 2011; 365:725-733.

31. Song DG, Powell DJ. Pro-survival signaling via CD27 costimulation drives effective CAR T-cell therapy. Oncoimmunology. 2012; 1:547-549.

32. Hartmann LC, Keeney GL, Lingle WL, Christianson TJ, Varghese B, Hillman D, Oberg AL, Low PS. Folate receptor overexpression is associated with poor outcome in breast cancer. Int J Cancer. 2007; 121:938-942.

33. Toffoli G, Russo A, Gallo A, Cernigoi C, Miotti S, Sorio R, Tumolo S, Boiocchi M. Expression of folate binding protein as a prognostic factor for response to platinum-containing chemotherapy and survival in human ovarian cancer. International journal of cancer Journal international $\mathrm{du}$ cancer. 1998; 79:121-126.

34. Maziarz KM, Monaco HL, Shen F, Ratnam M. Complete mapping of divergent amino acids responsible for differential ligand binding of folate receptors alpha and beta. The Journal of biological chemistry. 1999; 274:11086-11091.

35. Wu M, Gunning W, Ratnam M. Expression of folate receptor type alpha in relation to cell type, malignancy, and differentiation in ovary, uterus, and cervix. Cancer epidemiology, biomarkers \& prevention : a publication of the American Association for Cancer Research, cosponsored by the American Society of Preventive Oncology. 1999; 8:775-782.

36. Allard JE, Risinger JI, Morrison C, Young G, Rose GS, Fowler J, Berchuck A, Maxwell GL. Overexpression of folate binding protein is associated with shortened progression-free survival in uterine adenocarcinomas. Gynecologic oncology. 2007; 107:52-57.
37. Dainty LA, Risinger JI, Morrison C, Chandramouli GV, Bidus MA, Zahn C, Rose GS, Fowler J, Berchuck A, Maxwell GL. Overexpression of folate binding protein and mesothelin are associated with uterine serous carcinoma. Gynecologic oncology. 2007; 105:563-570.

38. Ross JF, Chaudhuri PK, Ratnam M. Differential regulation of folate receptor isoforms in normal and malignant tissues in vivo and in established cell lines. Physiologic and clinical implications. Cancer. 1994; 73:2432-2443.

39. Parker N, Turk MJ, Westrick E, Lewis JD, Low PS, Leamon CP. Folate receptor expression in carcinomas and normal tissues determined by a quantitative radioligand binding assay. Analytical biochemistry. 2005; 338:284-293.

40. Cannistra SA. Cancer of the ovary. The New England journal of medicine. 2004; 351:2519-2529.

41. Spear P, Barber A, Sentman CL. Collaboration of chimeric antigen receptor (CAR)-expressing $T$ cells and host $T$ cells for optimal elimination of established ovarian tumors. Oncoimmunology. 2013; 2:e23564.

42. Spear P, Barber A, Rynda-Apple A, Sentman CL. NKG2D CAR T-cell therapy inhibits the growth of NKG2D ligand heterogeneous tumors. Immunology and cell biology. 2013; 91:435-440.

43. Yoon SH, Lee JM, Cho HI, Kim EK, Kim HS, Park MY, Kim TG. Adoptive immunotherapy using human peripheral blood lymphocytes transferred with RNA encoding Her-2/ neu-specific chimeric immune receptor in ovarian cancer xenograft model. Cancer gene therapy. 2009; 16:489-497.

44. Kershaw MH, Westwood JA, Parker LL, Wang G, Eshhar Z, Mavroukakis SA, White DE, Wunderlich JR, Canevari S, Rogers-Freezer L, Chen CC, Yang JC, Rosenberg SA, Hwu P. A phase I study on adoptive immunotherapy using gene-modified $\mathrm{T}$ cells for ovarian cancer. Clin Cancer Res. 2006; 12:6106-6115.

45. Song D, Ye Q, Carpenito C, Poussin M, Wang LP, Ji C, Figini M, June CH, Coukos G Sr., Powell DJ Jr. Improved $\mathrm{T}$ cell survival provided by CD137 costimulatory signaling to folate receptor- redirected $\mathrm{T}$ cells results in tumor localization and eradication. Cancer Res. 2011; .

46. Maus MV, Haas AR, Beatty GL, Albelda SM, Levine BL, Liu X, Zhao Y, Kalos M, June CH. T Cells Expressing Chimeric Antigen Receptors Can Cause Anaphylaxis in Humans. Cancer Immunology Research. 2013; 1:26-31.

47. Figini M, Obici L, Mezzanzanica D, Griffiths A, Colnaghi MI, Winter G, Canevari S. Panning phage antibody libraries on cells: isolation of human Fab fragments against ovarian carcinoma using guided selection. Cancer research. 1998; 58:991-996.

48. Maus MV, Haas AR, Beatty GL, Albelda SM, Levine BL, Liu X, Zhao Y, Kalos M, June CH. T cells expressing chimeric antigen receptors can cause anaphylaxis in humans. Cancer Immunol Res. 2013; 1:26-31.

49. Sadelain M, Brentjens R, Riviere I. The promise and potential pitfalls of chimeric antigen receptors. Curr Opin Immunol. 2009; 21:215-223. 
50. Till BG, Jensen MC, Wang J, Chen EY, Wood BL, Greisman HA, Qian X, James SE, Raubitschek A, Forman SJ, Gopal AK, Pagel JM, Lindgren CG, Greenberg PD, Riddell SR, Press OW. Adoptive immunotherapy for indolent non-Hodgkin lymphoma and mantle cell lymphoma using genetically modified autologous CD20-specific T cells. Blood. 2008; 112:2261-2271.

51. Pule MA, Savoldo B, Myers GD, Rossig C, Russell HV, Dotti G, Huls MH, Liu E, Gee AP, Mei Z, Yvon E, Weiss HL, Liu H, Rooney CM, Heslop HE, Brenner MK. Virus-specific $\mathrm{T}$ cells engineered to coexpress tumorspecific receptors: persistence and antitumor activity in individuals with neuroblastoma. Nat Med. 2008; 14:1264-1270.

52. Kalos M, Levine BL, Porter DL, Katz S, Grupp SA, Bagg A, June CH. T cells with chimeric antigen receptors have potent antitumor effects and can establish memory in patients with advanced leukemia. Sci Transl Med. 2011; 3:95ra73.

53. Grupp SA, Kalos M, Barrett D, Aplenc R, Porter DL, Rheingold SR, Teachey DT, Chew A, Hauck B, Wright JF, Milone MC, Levine BL, June $\mathrm{CH}$. Chimeric antigen receptor-modified T cells for acute lymphoid leukemia. N Engl J Med. 2013; 368:1509-1518.

54. Hombach AA, Holzinger A, Abken H. The weal and woe of costimulation in the adoptive therapy of cancer with chimeric antigen receptor (CAR)-redirected T cells. Curr Mol Med. 2013; 13:1079-1088.

55. Xu XJ, Tang YM. Cytokine release syndrome in cancer immunotherapy with chimeric antigen receptor engineered T cells. Cancer Lett. 2014; 343:172-178.

56. Xu XJ, Zhao HZ, Tang YM. Efficacy and safety of adoptive immunotherapy using anti-CD19 chimeric antigen receptor transduced T-cells: a systematic review of phase I clinical trials. Leuk Lymphoma. 2013; 54:255-260.

57. Hacein-Bey-Abina S, Garrigue A, Wang GP, Soulier J, Lim A, Morillon E, Clappier E, Caccavelli L, Delabesse E, Beldjord K, Asnafi V, MacIntyre E, Dal Cortivo L, Radford I, Brousse N, Sigaux F, et al. Insertional oncogenesis in 4 patients after retrovirus-mediated gene therapy of SCID-X1. J Clin Invest. 2008; 118:3132-3142.

58. Ritchie DS, Neeson PJ, Khot A, Peinert S, Tai T, Tainton K, Chen K, Shin M, Wall DM, Honemann D, Gambell P, Westerman DA, Haurat J, Westwood JA, Scott AM, Kravets L, et al. Persistence and efficacy of second generation CAR T cell against the LeY antigen in acute myeloid leukemia. Mol Ther. 2013; 21:2122-2129.

59. Antony AC, Utley C, Van Horne KC, Kolhouse JF. Isolation and characterization of a folate receptor from human placenta. The Journal of biological chemistry. 1981; 256:9684-9692.

60. Zimmerman J. Folic acid transport in organ-cultured mucosa of human intestine. Evidence for distinct carriers. Gastroenterology. 1990; 99:964-972.
61. Birn H, Selhub J, Christensen EI. Internalization and intracellular transport of folate-binding protein in rat kidney proximal tubule. Am J Physiol. 1993; 264:C302-310.

62. Birn H, Nielsen S, Christensen EI. Internalization and apical-to-basolateral transport of folate in rat kidney proximal tubule. Am J Physiol. 1997; 272:F70-78.

63. Morshed KM, Ross DM, McMartin KE. Folate transport proteins mediate the bidirectional transport of 5-methyltetrahydrofolate in cultured human proximal tubule cells. J Nutr. 1997; 127:1137-1147.

64. Li J, Sausville EA, Klein PJ, Morgenstern D, Leamon CP, Messmann RA, LoRusso P. Clinical pharmacokinetics and exposure-toxicity relationship of a folate-Vinca alkaloid conjugate EC145 in cancer patients. J Clin Pharmacol. 2009; 49:1467-1476.

65. Konner JA, Bell-McGuinn KM, Sabbatini P, Hensley ML, Tew WP, Pandit-Taskar N, Vander Els N, Phillips MD, Schweizer C, Weil SC, Larson SM, Old LJ. Farletuzumab, a humanized monoclonal antibody against folate receptor alpha, in epithelial ovarian cancer: a phase I study. Clin Cancer Res. 2010; 16:5288-5295.

66. Canevari S, Stoter G, Arienti F, Bolis G, Colnaghi MI, Di Re EM, Eggermont AM, Goey SH, Gratama JW, Lamers $\mathrm{CH}$, et al. Regression of advanced ovarian carcinoma by intraperitoneal treatment with autologous $\mathrm{T}$ lymphocytes retargeted by a bispecific monoclonal antibody. J Natl Cancer Inst. 1995; 87:1463-1469.

67. Song DG, Ye Q, Poussin M, Liu L, Figini M, Powell DJ Jr. A fully human chimeric antigen receptor with potent activity against cancer cells but reduced risk for off-tumor toxicity. Oncotarget. 2015; .

68. Aoki Y, Takakuwa K, Kodama S, Tanaka K, Takahashi M, Tokunaga A, Takahashi T. Use of adoptive transfer of tumor-infiltrating lymphocytes alone or in combination with cisplatin-containing chemotherapy in patients with epithelial ovarian cancer. Cancer research. 1991; 51:1934-1939.

69. Song DG, Ye Q, Carpenito C, Poussin M, Wang LP, Ji C, Figini M, June CH, Coukos G, Powell DJ Jr. In vivo persistence, tumor localization, and antitumor activity of CAR-engineered T cells is enhanced by costimulatory signaling through CD137 (4-1BB). Cancer research. 2011; 71:4617-4627.

70. Xia W, Low PS. Folate-targeted therapies for cancer. J Med Chem. 2010; 53:6811-6824.

71. Maus MV, Haas AR, Beatty GL, Albelda SM, Levine BL, Liu X, Zhao Y, Kalos M, June CH. T cells expressing chimeric antigen receptors can cause anaphylaxis in humans. Cancer immunology research. 2013; 1:26-31.

72. Levine BL, Bernstein WB, Connors M, Craighead N, Lindsten T, Thompson CB, June CH. Effects of CD28 costimulation on long-term proliferation of CD4+ T cells in the absence of exogenous feeder cells. Journal of immunology. 1997; 159:5921-5930. 